\title{
Proteinase-Activated Receptor 4 Activation Triggers Cell Membrane Blebbing through RhoA and $\beta$-Arrestin $\mathrm{s}$
}

\author{
Christina M.G. Vanderboor, ${ }^{1}$ ๑P Pierre E. Thibeault, ${ }^{1}$ ๑ Kevin C.J. Nixon, Robert Gros, \\ Jamie Kramer, and (1)Rithwik Ramachandran \\ Department of Physiology and Pharmacology, Schulich School of Medicine and Dentistry, University of Western Ontario, \\ London, Ontario, Canada
}

Received September 4, 2019; accepted March 3, 2020

\begin{abstract}
Proteinase-activated receptors (PARs) are a four-member family of G-protein-coupled receptors that are activated via proteolysis. PAR4 is a member of this family that is cleaved and activated by serine proteinases such as thrombin, trypsin, and cathepsinG. PAR4 is expressed in a variety of tissues and cell types, including platelets, vascular smooth muscle cells, and neuronal cells. In studying PAR4 signaling and trafficking, we observed dynamic changes in the cell membrane, with spherical membrane protrusions that resemble plasma membrane blebbing. Since nonapoptotic membrane blebbing is now recognized as an important regulator of cell migration, cancer cell invasion, and vesicular content release, we sought to elucidate the signaling pathway downstream of PAR4 activation that leads to such events. Using a combination of pharmacological inhibition and CRISPR/CRISPR-associated protein 9 (Cas9)-mediated
\end{abstract}

gene editing approaches, we establish that PAR4-dependent membrane blebbing occurs independently of the $\mathrm{G} \alpha_{\mathrm{q} / 11^{-}}$and $\mathrm{G} \alpha_{\mathrm{i}}$-signaling pathways and is dependent on signaling via the $\beta$-arrestin-1/2 and Ras homolog family member $A$ (RhoA) signaling pathways. Together these studies provide further mechanistic insight into PAR4 regulation of cellular function.

\section{SIGNIFICANCE STATEMENT}

We find that the thrombin receptor PAR4 triggers cell membrane blebbing in a RhoA-and $\beta$-arrestin-dependent manner. In addition to identifying novel cellular responses mediated by PAR4, these data provide further evidence for biased signaling in PAR4 since membrane blebbing was dependent on some, but not all, signaling pathways activated by PAR4.

\section{Introduction}

Proteinase-activated receptors (PARs) are a four-member family of G-protein-coupled receptors (GPCRs). PARs are unique among GPCRs because they are activated via proteolytic unmasking of a receptor-activating "tethered ligand" that interacts intramolecularly with the orthosteric ligand binding pocket to trigger signaling (Ramachandran et al., 2012). PAR4, the most recently identified member of this family (Xu et al., 1998), is expressed in a variety of tissues and cell types, including the platelets, vascular smooth muscle cells, neuronal cells, and some cancer cells.

This work was supported by grants to R.R. from the Canadian Institutes of Health Research [Funding reference \#376560]. P.E.T. and K.C.J.N. were supported by Queen Elizabeth II Graduate Scholarships in Science and Technology from the Government of Ontario.

An earlier version of this paper appears in bioRxiv under the DOI: 10.1101/ 746677

${ }^{1}$ C.M.G.V. and P.E.T. have contributed equally.

https://doi.org/10.1124/mol.119.118232.

S This article has supplemental material available at molpharm. aspetjournals.org.
Much work has been done to develop PAR1- and PAR4targeted compounds as antiplatelet agents. Both PAR1 and PAR4 are expressed in human platelets, and both of these receptors are activated by the coagulation cascade enzyme thrombin. Importantly, although PAR1 and PAR4 appear to serve different roles in the platelet activation process (Kahn et al., 1999), with PAR1 as the high-affinity thrombin receptor playing an initiating role and the lower-affinity thrombin receptor PAR4 serving to consolidate and propagate the clot (Kahn et al., 1999). The PAR1 antagonist voropaxar (ZONTIVITY), although highly effective in reducing cardiovascular complications, exhibited significant side effects with an elevated risk for bleeding, including in the brain (Morrow et al., 2012). This has spurred recent efforts to target PAR4. Recent work with small-molecule PAR4 antagonists has supported the idea that PAR4 antagonists are effective in reducing platelet-rich thrombus formation in human platelets ex vivo and in rodent and nonhuman primate models in vivo (Wong et al., 2017). In nonhuman primate models, PAR4 blockade was associated with low bleeding liability and had a markedly wider therapeutic

ABBREVIATIONS: BRET, bioluminescent resonance energy transfer; Cas9, CRISPR-associated protein 9; DMB-forskolin, 7- $\beta$-Deacetyl-7 $\beta[\gamma-$ (morpholino-butyryl] forskolin; dRS-PAR4, mutant PAR4 receptor with an eight-amino acid C-terminal deletion; GPCR, G-protein-coupled receptor; HEK-293, human embryonic kidney 293 cells; KO, knockout; PAR, proteinase-activated receptor; PKC, protein kinase C; PTX, pertussis toxin; RhoA, Ras homolog family member A; Rluc, Renilla luciferase; ROCK, Rho-associated protein kinase; SHR, spontaneously hypertensive; VSMC, vascular smooth muscle cells; WKY, Wistar Kyoto; YFP, yellow fluorescent protein. 
window compared with the commonly used antiplatelet agent clopidogrel (Wong et al., 2017).

In keeping with emerging literature for other GPCRs, we now know that activated PAR4 can directly couple to multiple G-protein-signaling pathways, including the $\mathrm{G} \alpha \alpha_{\mathrm{q} / 11}$ and $\mathrm{G} \alpha_{12 / 13}$ pathway (Woulfe, 2005; Kim et al., 2006), but is thought not to engage $\mathrm{G} \alpha_{\mathrm{i}}$-dependent signaling pathways (Kim et al., 2006). PAR4 can also recruit and signal through $\beta$-arrestins (Li et al., 2011; Ramachandran et al., 2017). In recent work, we identified a C-terminal motif in PAR4 that was critical for PAR4 signaling through the $\mathrm{G} \alpha_{\mathrm{q} / 11}$ calcium signaling pathway and for recruiting $\beta$-arrestin-1/-2 (Ramachandran et al., 2017). The mutant receptor with an eight-amino acid C-terminal deletion (dRS-PAR4) failed to internalize after activation with the PAR4 agonists thrombin or AYPGKF-NH $\mathrm{N}_{2}$, suggesting a role for $\beta$-arrestins in PAR4 trafficking. A pepducin targeting this C-terminal motif was also effective in attenuating PAR4-dependent platelet aggregation and thrombosis in vivo (Ramachandran et al., 2017). These recent findings point to the exciting possibility that it might be possible to therapeutically target PAR4 signaling in a pathway-specific manner. The present study was spurred by our observations that PAR4 activation rapidly triggered the formation of dynamic membrane blebs, which were absent in dRS-PAR4-expressing cells.

Nonapoptotic plasma membrane blebbing is now recognized as a feature of various cellular processes, including directional cellular migration during development, cancer cell migration and invasion, neuronal cell remodeling, and vesicular content release (Charras, 2008; Charras and Paluch, 2008; Charras et al., 2008). Blebs are formed when the plasma membrane transiently detaches from the underlying actin filaments, resulting in intracellular pressure-mediated spherical membrane protrusions (Charras et al., 2008; Tinevez et al., 2009). The reassembly of actin filaments limits the expansion of blebs and actin polymerization while actomyosin contraction drives the retraction of the blebs (Charras et al., 2008). The molecular signals that trigger the formation of membrane blebs are beginning to be understood and include signaling from cell surface receptors such as GPCRs and receptor tyrosine kinases (Hagmann et al., 1999; Lawrenson et al., 2002; Godin and Ferguson, 2010; Chen et al., 2012; LaserAzogui et al., 2014). A role for multiple Rho isoforms has also been described in regulating various aspects of bleb formation and retraction (Pinner and Sahai, 2008; Aoki et al., 2016; Gong et al., 2018). Previous work has described regulation of Rho signaling by GPCRs in both a G-protein- and $\beta$-arrestin-dependent manner (Sah et al., 2000; Barnes et al., 2005; Anthony et al., 2011).

Here, we examine in detail the pathways leading from PAR4 to the formation of membrane blebs. We find that inhibition of $\mathrm{G} \alpha_{\mathrm{q} / 11}$ signaling had no effect on the formation of PAR4-triggered membrane blebs, whereas blockade of $\beta$-arrestin-1/2- or Rho-dependent signaling significantly reduced blebbing.

\section{Materials and Methods}

Materials. Unless otherwise noted, all chemicals were purchased from Thermo Fisher (Waltham, MA). Peptide ligands were custom synthesized by Genscript (Piscataway, NJ) at greater than $95 \%$ purity. Thrombin was purchased from Calbiochem (Oakville, ON), and coelanterazine-h was from Nanolight Technology (Pinetop, AZ). All antibodies (anti- $\beta$-arrestin- $1 / 2$, anti-RhoA, anti-actin, anti-rabbitHorseradish Peroxidase) used in this study were purchased from Cell Signaling Technologies. YM254890 was from Wako chemicals (Richmond, VA), GSK269962 was from Tocris (Oakville, ON), and all other chemicals were from Sigma-Aldrich (Oakville, ON).

Cell Culture and Transfections. Human Embryonic Kidney 293 (HEK-293; ATCC) cells were maintained in Dulbecco's modified Eagle's medium (Gibco) with $10 \%$ FBS (Gibco), $1 \%$ penicillin-streptomycin (Gibco), and $1 \%$ sodium pyruvate (Gibco). Cells stably expressing PAR4-YFP or dRS-PAR4-YFP were maintained in the above media supplemented with $600 \mu \mathrm{g} / \mathrm{ml}$ of geneticin (Gibco). dRS-PAR4-YFPexpressing HEK-293 cells have been previously described (Ramachandran et al. 2017). PAR1-KO-PAR4-YFP-HEK-293 (Mihara et al., 2016) and $\beta$-arrestin-1/2-KO HEK-293 cells (Thibeault et al., 2020) have been previously characterized. Cells were transiently transfected using a modified calcium phosphate method (Ferguson and Caron, 2004). Experiments were performed 48 hours posttransfection. Primary rat smooth muscle cells were isolated and cultured as previously described (Gros et al., 2006).

Constructs. PAR4-YFP and dRS-PAR4-YFP have been previously described (Ramachandran et al., 2017). Dominant negative $\mathrm{G} \alpha_{12} \mathrm{Q}^{231} \mathrm{~L} / \mathrm{D}^{299} \mathrm{~N}$ (plasmid \# GNA12000X0) and $\mathrm{G} \alpha_{13} \mathrm{Q}^{226} \mathrm{~L} / \mathrm{D}^{294} \mathrm{~N}$ (plasmid \# GNA13000X0) were obtained from the cDNA resource center (www.cdna.org) (Yang et al., 2005; Lauckner et al., 2008; Goupil et al., 2010). pGloSensor-22F cAMP (Promega) and pcDNA3.1 $\alpha-2$ adrenergic receptor plasmids were a kind gift from Dr. Peter Chidiac. GFP-N2-PKCgamma (PKC-GFP) was a gift from Tobias Meyer (plasmid \# 21204; Addgene).

Creation of RhoA Knockout Cells. RhoA HEK-293 cells (RhoA-KO HEK) were generated using CRISPR/CRISPR-associated protein 9 (Cas9)-mediated gene targeting. Guides targeting RhoA were designed using a web-based design tool as previously described (Cong et al., 2013; Hsu et al., 2013). Gene-specific guides for RhoA (CGAGTTTGCGACTCG CGGAC, CGGTCCGCGAGTCGCAAACT, GAGTCCAGCCTCTTCGCG CC, GACTCGCGGACCGGCGTCCC) were ligated into the PX458 vector (a kind gift from Dr. Feng Zhang, MIT, plasmid \# 48138; Addgene), verified by direct sequencing, and transfected in HEK cells via the calcium phosphate method. At 48 hours posttransfection, GFPexpressing single cells were flow-sorted into individual wells of a 96 -well plate (Becton Dickinson FACSAria III). Clonal cells from individual wells were screened by Western blotting to identify cell lines that were deficient in RhoA (Supplemental Fig. 1).

Confocal Microscopy. Cells were plated onto glass-bottom 35-mm dishes (MatTek, Ashland, MA) and imaged using a Zeiss confocal Laser Scanning Microscope 510 Meta Non-Linear Optics. Yellow fluorescent protein was excited with 514 laser line and visualized with 535-560 filter set. mCherry fluorophore was excited with 543 laser line and visualized with 560-590. GFP was excited with 488 laser line and visualized with 530-560 filter set. Cell shape change experiments were conducted as follows. HEK-293 cells stably expressing C-terminally enhanced yellow fluorescent protein-tagged PAR4, CRISPR/Cas9 knockout cell lines, or transiently transfected cells were plated into three to four glass-bottom dishes and subsequently treated with vehicle or inhibitor, as indicated in the figure legends. Plates were then placed on a heated stage on the microscope, and PAR4-YFP was activated with AYPGKF-NH $\mathrm{NH}_{2}(30 \mu \mathrm{M})$ or thrombin (3 Units/ml), as indicated in the figure legends. Over 10 minutes, 6-12 images per dish were taken. This represented one independent experiment and was repeated three to five times on different days with newly cultured cells. For experiments that used stably expressing cell lines or stable knockout cell lines, an experiment was considered an independent replicate when it was conducted on a different day with cells that were cultured on different days. Images were scored twice, once by the experimenter and once by a blinded individual, and statistical analysis was used to ensure that scoring was not different between observers. In all cases, there were no significant differences between 
the observer scores. Cells were scored by manually counting the number of cells displaying membrane protrusions (indicated by arrows in the figures) versus cells that did not display any membrane protrusions. The "degree" of blebbing was not studied here.

Bioluminescent Resonance Energy Transfer Assay for $\boldsymbol{\beta}$-Arrestin-1/2 Recruitment. Bioluminescent resonance energy transfer was measured between C-terminally YFP-tagged PAR4 (Ramachandran et al., 2017) and Renilla luciferase (Rluc)-tagged $\beta$-arrestin-1 or $\beta$-arrestin-2 (a kind gift from Dr. Michel Bouvier, U. de Montreal) after 20 minutes of receptor activation, as described in previous studies (Ramachandran et al., 2009). Briefly, PAR4-YFP $(1 \mu \mathrm{g})$ and $\beta$-arrestin-1-Rluc or -2-Rluc) $(0.1 \mu \mathrm{g})$ were transiently transfected in cells plated in a six-well plate for 24 hours. Cells were replated into white 96 -well culture plates and cultured for a further 24 hours. Interactions between PAR4 and $\beta$-arrestin- $1 / 2$ were detected by measuring the bioluminescent resonance energy transfer (BRET) ratio at timed intervals over 20 minutes after the addition of h-coelenterazine (5 $\mu \mathrm{M}$; Nanolight Technology) on a Mithras LB940 plate reader (Berthold Technologies) with the appropriate BRET filters.

gloSensor cAMP Assay. HEK-293 cells were transfected with $\alpha_{2 \mathrm{~A}}$ adrenergic receptor $(1 \mu \mathrm{g})$ and pGloSensor-22F cAMP sensor $(1 \mu \mathrm{g})$ plasmids using the X-tremeGENE 9 transfection reagent (Sigma). Cells were plated into a white 96-well plate (Corning) 24 hours after transfection along with either vehicle control or pertussis toxin (PTX, $100 \mathrm{ng} / \mathrm{ml}$ ) and incubated overnight (approximately 18 hours prior to experiment). Forty-eight hours posttransfection, cell media were replaced with minimal essential medium (no phenol red) supplemented with bovine serum albumin $(0.1 \% \mathrm{w} / \mathrm{v})$, D-luciferin $(2 \mathrm{mM})$, and HEPES $(20 \mathrm{mM})$ for 2 hours. At 15 minutes prior to measurement, 3-isobutyl-1-methylxanthine $(200 \mu \mathrm{M})$ was added into wells. $\alpha_{2 \mathrm{~A}}$ agonist 5-Bromo-6-(2-imidazolin-2-ylamino) quinoxaline tartrate (UK 14, 304, $1 \mathrm{nM}$ ) was added 5 minutes prior to measurement. $7-\beta$-Deacetyl-7 $\beta$ [ $\gamma$-(morpholino-butyryl] butyryl $]$ forskolin (DMB-forskolin, $2 \mu \mathrm{M}$ ) was added to each well to stimulate cAMP production. Luminescence was recorded every 2.5 minutes for 30 minutes on a Mithras LB940 plate reader (Bethold Technologies), and increase in luminescence over time was graphed. These experiments were conducted to determine the efficacy of the pertussis toxin lot and concentration used in both BRET and confocal experiments (Supplemental Fig. 2).

Statistical Analysis. All data shown are presented as means with S.D. Statistical analysis of data and curve fitting were done with Prism 7 software (GraphPad Software, San Diego, CA). Statistical tests are listed in the figure legends. For studies done with inhibitors, a paired $t$ test was used since the cell population is the same for both vehicle- and drug-treated conditions. For studies comparing different cell lines, an unpaired $t$ test was used, since observations were from different cell populations. Finally, data were tested for normality using a Shapiro-Wilk test, and for data that were not normally distributed (nonparametric), a subsequent nonparametric test was used to determine significance.

\section{Results}

Activation of PAR4 Elicits Cell Shape Changes that Are Dependent on a C-Tail Eight-Amino Acid Sequence. Stimulation of plasma membrane-localized PAR4-YFP in HEK-293 cells stably expressing PAR4-YFP (Fig. 1A) with the PAR4-specific peptide agonist (AYPGKF- $\mathrm{NH}_{2}$ ) resulted in cell shape changes that resembled membrane protrusions and are illustrated in Fig. 1. PAR4-expressing cells treated with AYPGKF- $\mathrm{NH}_{2}(30 \mu \mathrm{M})$ displayed protrusions forming at the plasma membrane, indicated by arrows (Fig. 1B). These structures resemble membrane blebs and began to form around 2 minutes post-agonist stimulation
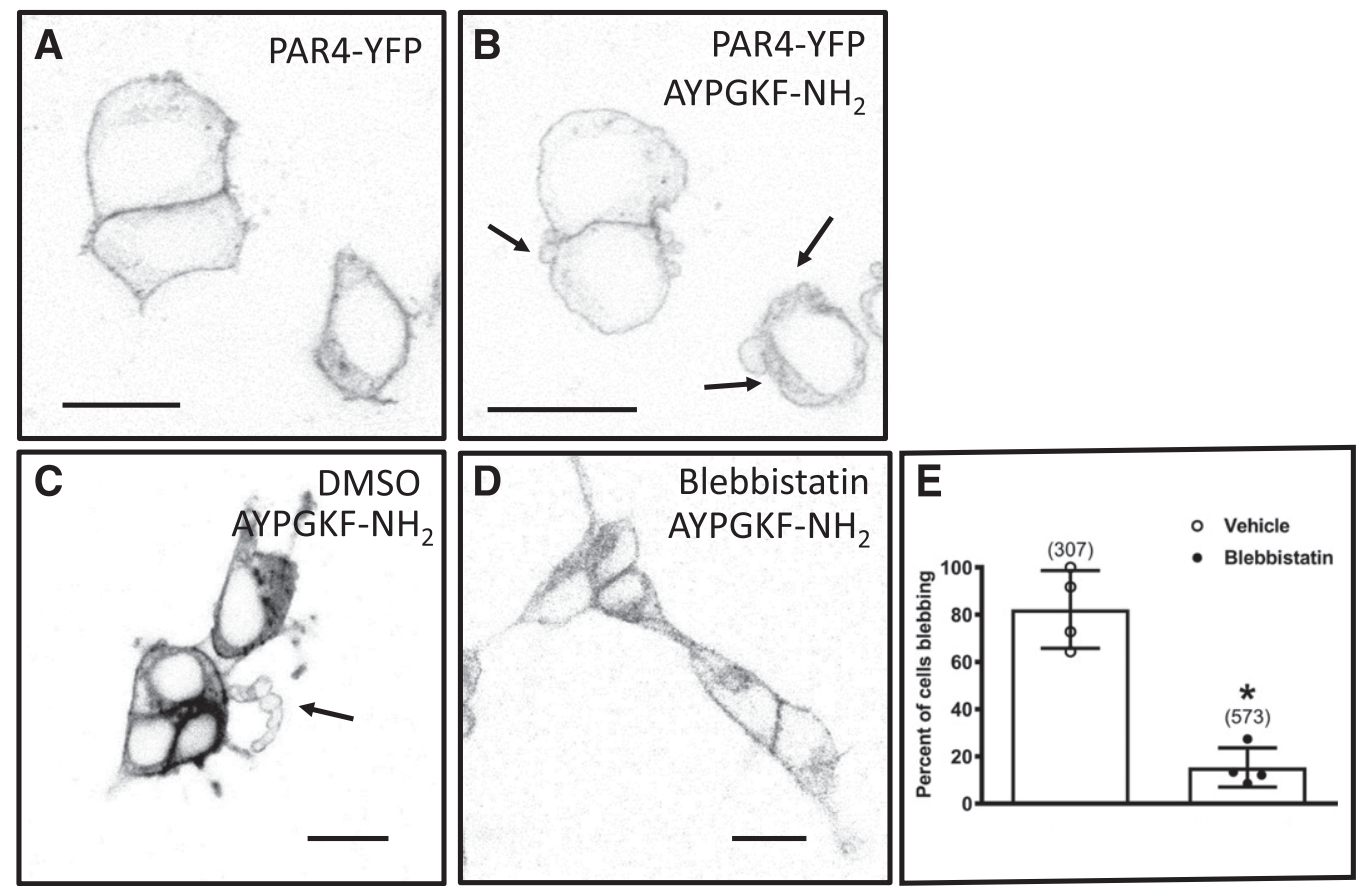

Fig. 1. Activation of PAR4 mediates a cell shape change response. Representative confocal micrographs showing HEK-293 cell stably expressing PAR4YFP (A and B). Cells were treated with AYPGKF-NH $2(30 \mu \mathrm{M})$ for 2 minutes prior to imaging. Size bars are $20 \mu \mathrm{m}$, and arrows indicate membranemembrane protrusions (blebs). HEK-293 cells stably expressing PAR4-YFP (C-E) were incubated in either DMSO (C) or blebbistatin (10 $\mu$ M) (B) for 15 minutes prior to a 2-minute treatment with AYPGKF- $\mathrm{NH}_{2}(30 \mu \mathrm{M})$ followed by confocal microscopy imaging. Arrows show bleb formation; size bars are $20 \mu \mathrm{m}$. (E) Percentage of cells stably expressing PAR4-YFP that displayed membrane blebbing in response to $\mathrm{AYPGKF}^{-\mathrm{NH}_{2}}(30 \mu \mathrm{M})$ treatment in the presence of either DMSO or blebbistatin. Numbers above the bars indicate the total number of cells scored for blebbing response. Data represent mean \pm S.D. of four independent experiments, and the asterisk shows significant differences; paired $t$ test, $P<0.05$. 
and lasted for up to 30 minutes in the presence of AYPGKF$\mathrm{NH}_{2}(30 \mu \mathrm{M})$. To further verify that the cytoskeletal changes were indeed membrane blebs, we examined the effect of treating cells with blebbistatin, a small-molecule inhibitor of myosin II ATPase (Cheung et al., 2002; Straight et al., 2003), which functions by locking actin heads in a low-actin affinity complex (Kovács et al., 2004) and is reported to inhibit nonapoptotic membrane blebbing. Incubation of cells with blebbistatin significantly reduced the AYPGKF- $\mathrm{NH}_{2}$-stimulated membrane bleb response in PAR4-YFP-expressing HEK-293 cells $(15.37 \% \pm 8.29 \%)$ (Fig. $1, \mathrm{D}$ and $\mathrm{E})$. In contrast, PAR4YFP-expressing cells treated with vehicle control (DMSO) (Fig. 1C) displayed membrane blebs with a mean of $82.25 \% \pm$ $16.47 \%$. In a recent study, we described a mutant PAR4 receptor lacking eight amino acids from the C-tail, dRS-PAR4YFP (Ramachandran et al., 2017). We observed that in contrast to the wild-type receptor, dRS-PAR4-YFP-expressing cells displayed significantly less blebbing in response to AYPGKF$\mathrm{NH}_{2}(30 \mu \mathrm{M})$ treatment (Fig. 2, A-C). HEK-293 cells stably expressing wild-type PAR4-YFP displayed membrane blebbing $(82.33 \% \pm 2.08 \%)$, as opposed to $8.2 \% \pm 4.07 \%$ dRSPAR4-YFP-expressing cells, indicating that PAR4-triggered membrane blebbing required the activation of signaling pathways that are dependent on the eight-amino acid sequence in the C-tail of PAR4. Previously, we established that dRSPAR4-YFP does not couple to $\mathrm{G} \alpha_{\mathrm{q} / 11}$ and is unable to recruit $\beta$-arrestins in response to thrombin or AYPGKF-NH $\mathrm{N}_{2}$ activation (Ramachandran et al., 2017). Since this mutant receptor is also unable to activate blebbing, we hypothesized that PAR4 cell shape changes are $\mathrm{G} \alpha_{\mathrm{q} / 11^{-}}$and/or $\beta$-arrestin-dependent and examined the effect of blocking these pathways on bleb formation.

PAR4-Mediated Cell Shape Change Is G $\alpha_{q / 11^{-}}$and $\mathbf{G} \boldsymbol{\alpha}_{\mathbf{i}}$-Independent. To determine whether PAR4-triggered blebbing is $\mathrm{G} \alpha_{\mathrm{q} / 11^{-}}$-dependent, we treated cells with the potent and selective $\mathrm{G} \alpha_{\mathrm{q} / 11}$ inhibitor YM254890 (Taniguchi et al., 2004). It is well established that GPCRs couple to $\mathrm{G} \alpha_{\mathrm{q} / 11}$ to mobilize calcium and activate protein kinase C (PKC) (Exton, 1996; Wettschureck and Offermanns, 2005). Activated PKC translocation from the cytosol to the plasma membrane can be observed to monitor this process (Dale et al., 2001; Policha et al., 2006). We employed this assay to confirm the efficacy of YM-254890 in inhibiting $\mathrm{G} \alpha_{\mathrm{q} / 11}$ signaling through PAR4. Cells were transiently transfected with PAR4-mCherry and
PKC-GFP. PAR4 expression was observed at the cell membrane, and PKC expression was evident in the cytoplasm in resting cells (Fig. 3A). Upon treatment with AYPGKF-NH $\mathrm{N}_{2}(30$ $\mu \mathrm{M})$, PKC-GFP translocated to the membrane (Fig. 3B), and blebbing responses were observed, as before (Fig. 3C). In cells treated with YM254890 (100 nM), PKC-GFP failed to translocate to the membrane after treatment with AYPGKF- $\mathrm{NH}_{2}$ (Fig. 3, D-F). YM254890 (100 nM)-treated cells, however, maintained their ability to bleb in response to AYPGKF- $\mathrm{NH}_{2}$ (Fig. 3, D-F). The role of $\mathrm{G} \alpha_{\mathrm{q} / 11}$ in PAR4-mediated blebbing was further quantified in HEK-293 cells stably expressing PAR4-YFP treated with either DMSO vehicle or YM254890 prior to stimulation with AYPGKF-NH $\mathrm{N}_{2}(30 \mu \mathrm{M})$. Blebbing in vehicle-treated cells was not significantly different from cells treated with YM254890: $81.0 \% \pm 4.5 \%$ and $77.0 \% \pm 2.5 \%$, respectively (Fig. 3G). These data indicate that YM254890 functionally blocks $\mathrm{G} \alpha_{\mathrm{q} / 11}$ signaling, as indicated by a lack of PKC translocation, but does not block cell shape changes mediated by PAR4 activation.

HEK-293 cells transiently expressing PAR4-mCherry with PKC-GFP showed that activation of PAR4-mCherry with AYPGKF- $\mathrm{NH}_{2}$ causes a translocation of PKC-GFP from the cytosol (Fig. 4A) to the plasma membrane (Fig. 4B). In contrast, HEK-293 cells transiently expressing dRS-PAR4mCherry with PKC-GFP showed that activation of dRS-PAR4mCherry does not cause a redistribution of PKC-GFP to the membrane (Fig. 4, C and D). Although PKC activation is downstream of $\mathrm{G} \alpha_{\mathrm{q} / 11}$, since dRS-PAR4 does not activate PKC and does not elicit cell shape changes, we tested PKC for a potential role in mediating PAR4-mediated cell shape changes. HEK-293 cells stably expressing PAR4-YFP were treated with the PKC inhibitor Gö6983 (Gschwendt et al., 1996) prior to stimulation with AYPGKF- $\mathrm{NH}_{2}(30 \mu \mathrm{M})$ and visualization by confocal microscopy (Fig. 4, E and F). There was no significant difference in the number of vehicle-treated (DMSO) cells displaying blebbing when compared with cells treated with Gö6983 in response to AYPGKF- $\mathrm{NH}_{2}(74.5 \% \pm 4.6 \%$ and $72.2 \% \pm 9.2 \%$ ) (Fig. 4G). These data suggest, then, that neither $\mathrm{G} \alpha_{\mathrm{q} / 11}$ nor PKC facilitates PAR4-mediated cell shape changes.

After ruling out $\mathrm{G} \alpha_{\mathrm{q} / 11}$ as a potential signaling partner for PAR4-mediated membrane blebs, we tested $\mathrm{G} \alpha_{\mathrm{i}}$ recruitment as a potential regulator of these responses through inhibition of $\mathrm{G} \alpha \alpha_{\mathrm{i}}$ signaling with PTX. HEK-293 cells stably expressing

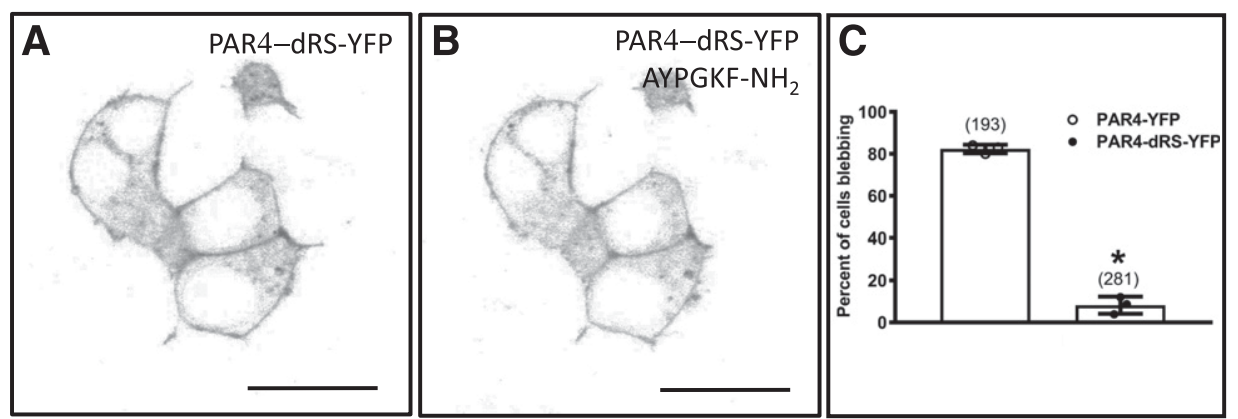

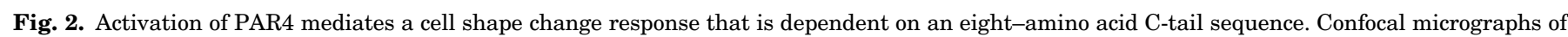

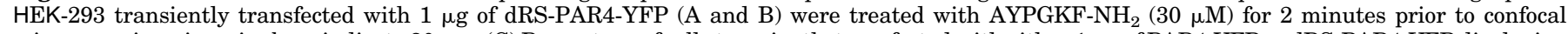

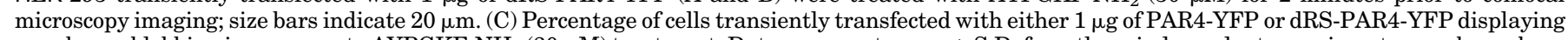

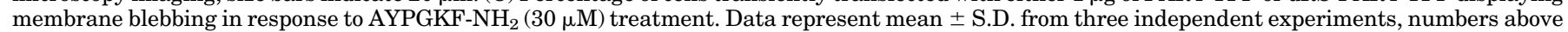
the bars indicate total number of cells scored for blebbing response, and the asterisk indicates statistical significance; unpaired $t$ test, $P<0.005$. 

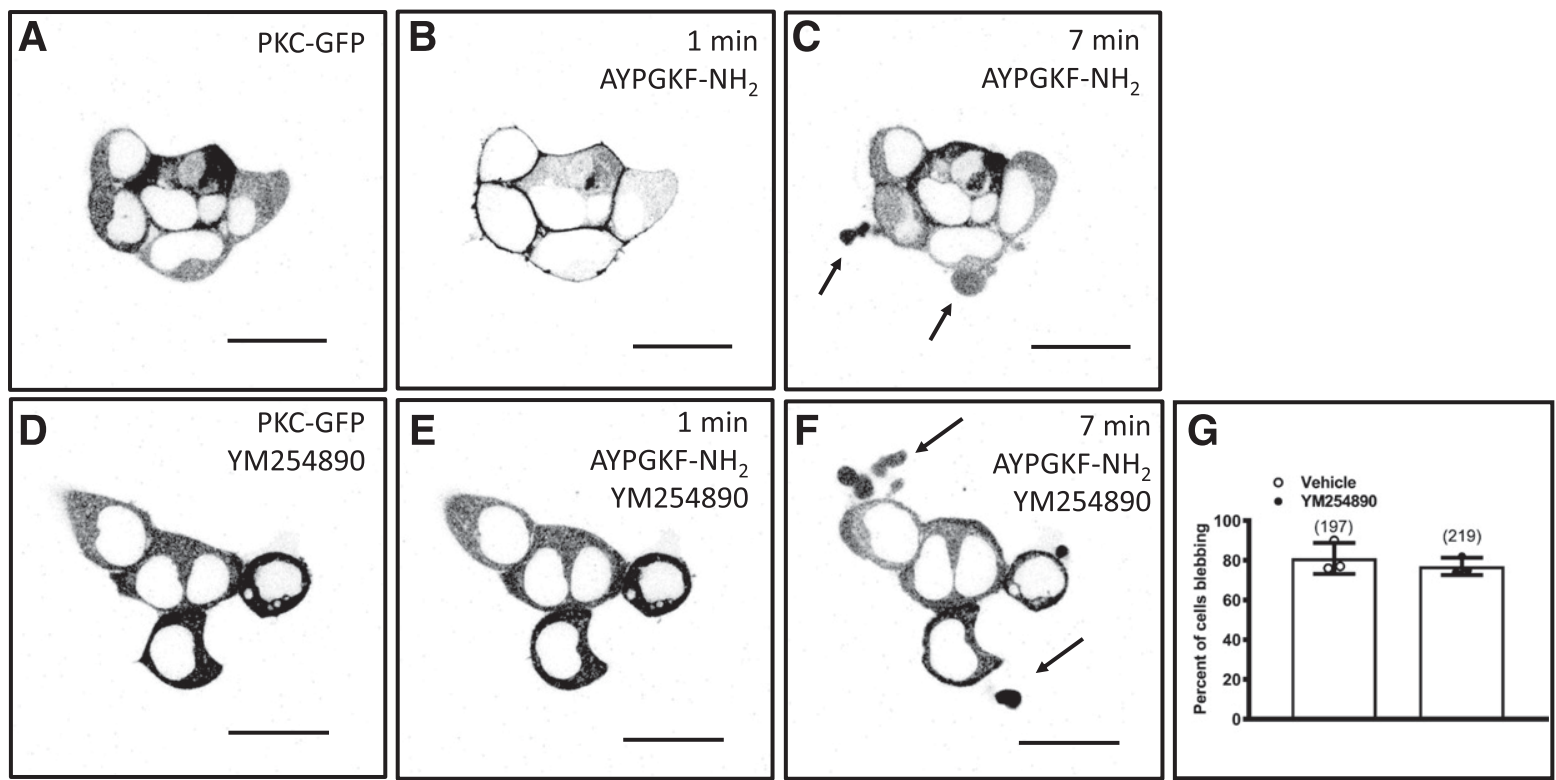

Fig. 3. PAR4-mediated cell shape change is $\mathrm{G} \alpha_{\mathrm{q} / 11}$-independent. Confocal micrographs of HEK-293 cells transiently transfected with PAR4-mCherry (not shown) and with $1 \mu \mathrm{g}$ of PKC-GFP (shown in black) were treated with DMSO followed by stimulation with AYPGKF-NH 2 (30 $\mu$ M) $(\mathrm{A}-\mathrm{C})$ or treated with YM254890 (100 nM), a G $\alpha_{\text {q } 11}$ inhibitor, for 20 minutes prior to addtion of AYPGKF-NH $(30 \mu \mathrm{M})(\mathrm{D}-\mathrm{F})$. Arrows show bleb formation; size bars are $20 \mu \mathrm{m}$. (G) Percentage of cells transiently transfected with $1 \mu \mathrm{g}$ each of PAR4-mCherry and PKC-GFP displaying membrane blebbing in response to AYPGKF-NH $2(30 \mu \mathrm{M})$ in the presence of either DMSO (vehicle) or YM254890 (100 nM). Numbers above the bars indicate total number of cells scored. Data represent mean \pm S.D. of three independent experiments; not significantly different, paired $t$ test.

PAR4-YFP were incubated with pertussis toxin $(100 \mathrm{ng} / \mathrm{ml})$ for 18 hours prior to stimulating the cells with AYPGKF-NH (30 $\mu \mathrm{M}$; Fig. 5, A and B). We did not observe any reduction in the number of cells that displayed blebbing when compared

PAR4-mCherry
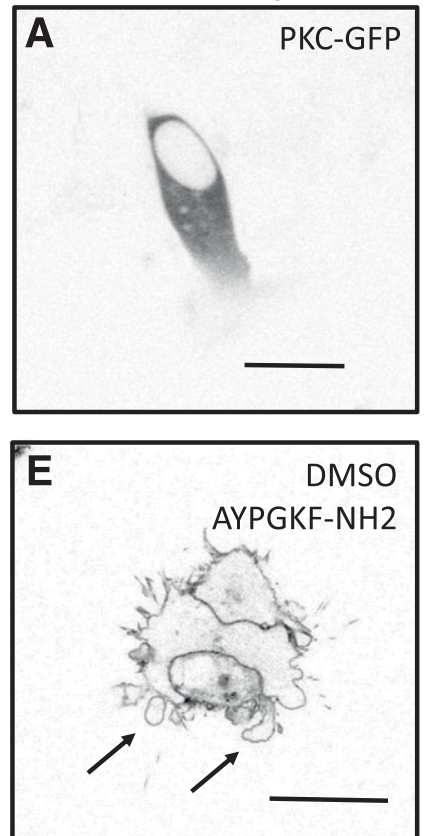

with cells incubated with vehicle control (saline) $(76.3 \% \pm$ $6.00 \%$ and $78.0 \% \pm 8.14 \%$, respectively) (Fig. 5C). Since we did not see an effect of PTX on membrane blebbing, we tested the efficacy of the toxin. To accomplish this, we employed

\section{dRS-PAR4-mCherry}
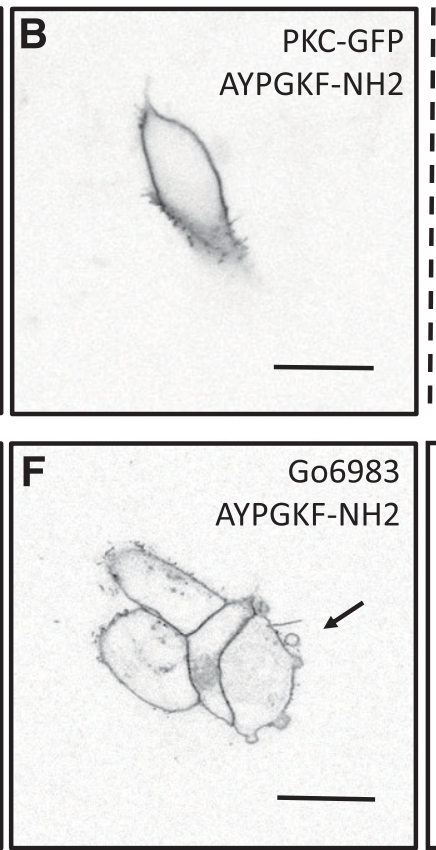
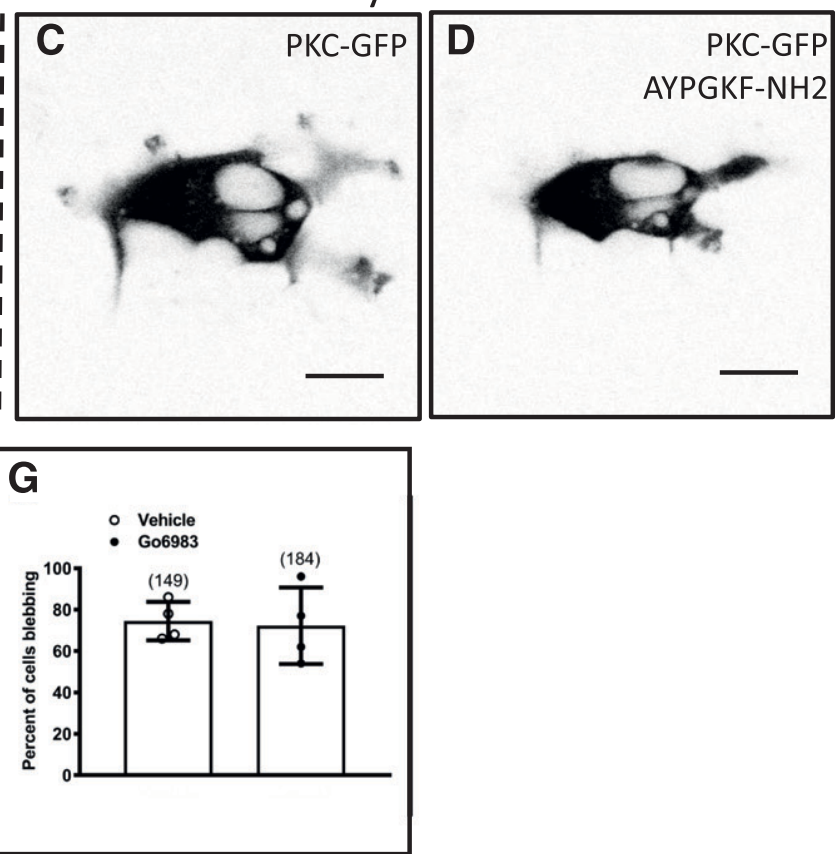

Fig. 4. PAR4-mediated cell shape change is PKC-independent. Confocal micrographs of HEK-293 cells transiently transfected with $1 \mu \mathrm{g}$ each of PAR4-mCherry (not shown) and PKC-GFP (shown in black) (A and B) or $1 \mu \mathrm{g}$ each of dRS-PAR4-mCherry (not shown) with PKC-GFP (shown in black) $(\mathrm{C}$ and D) were treated with AYPGKF-NH $2(30 \mu \mathrm{M})$ and imaged by confocal microscopy; size bars are $20 \mu \mathrm{m}$. HEK-293 cells stably expressing PAR4-YFP were incubated with DMSO (E) or with Gö6983 (100 nM), a PKC inhibitor, for 15 minutes (F) prior to a 2-minute stimulation with AYPGKF-NH ${ }_{2}(30 \mu M$ ) and subsequent imaging by confocal microscopy. (G) Percentage of cells stably expressing PAR4-YFP displaying membrane blebbing in response to AYPGKF-NH ${ }_{2}(30 \mu \mathrm{M})$ treatment in the presence of either DMSO (vehicle) or Gö6983 $(100 \mathrm{nM})$. Numbers above the bars indicate total number of cells scored. Data represent mean \pm S.D. of four indipendent experiments; not significantly different, paired $t$ test. 

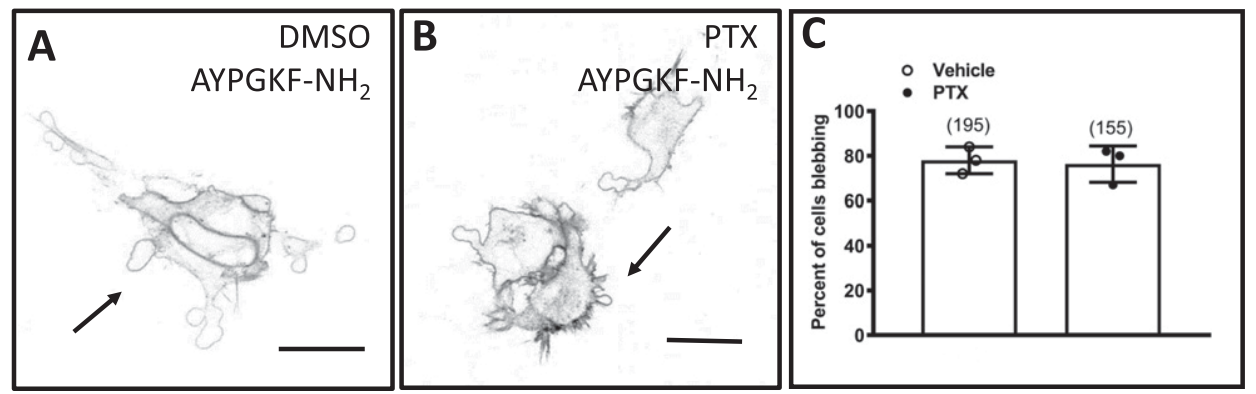

Fig. 5. PAR4-mediated cell shape change is $\mathrm{G} \alpha_{\mathrm{i}}$-independent. Confocal micrographs showing HEK-293 cells stably expressing PAR4-YFP were incubated with either DMSO (A) or (B) PTX (100 ng/ml), a G $\alpha_{\mathrm{i}}$ inhibitor, for 18 hours prior to AYPGKF-NH 2 (30 $\mu$ M) treatment of 2 minutes and subsequent confocal imaging. Arrows indicate bleb formation; size bars are $20 \mu \mathrm{m}$. (C) Percentage of cells stably expressing PAR4-YFP and displaying membrane blebbing in response to AYPGKF-NH $(30 \mu \mathrm{M})$ in the presence of either DMSO (vehicle) or PTX (100 ng/ml). Numbers above the bars indicate total number of cells scored. Data represent mean \pm S.D. of three independent experiments; not significantly different, paired $t$ test.

a luminescence-based assay using the pGloSensor-22F to measure the inhibition of cAMP production in response to agonist stimulation of the $\mathrm{G} \alpha_{\mathrm{i}}$-coupled $\alpha$-2 adrenergic $\left(\alpha_{2 \mathrm{~A}}\right)$ receptor. Loss of $\alpha_{2 \mathrm{~A}^{-}}$-stimulated, $\mathrm{G} \alpha_{\mathrm{i}}$-coupled inhibition of cAMP production by pertussis toxin-mediated inhibition of $\mathrm{G} \alpha_{\mathrm{i}}$ (thus, no inhibition of cAMP production) indicates efficacy of pertussis toxin. In HEK-293 cells treated with DMB-forskolin to induce cAMP production, treatment of cells with pertussis toxin or with vehicle control showed no significant reduction on cAMP production, indicating that PTX does not reduce cAMP independently of $\mathrm{G} \alpha_{\mathrm{i}}$ (Supplemental Fig. 2, A and C). Agonist stimulation of the $\mathrm{G} \alpha_{\mathrm{i}}$-coupled $\alpha_{2 \mathrm{~A}}$ receptor with UK 14, 304,
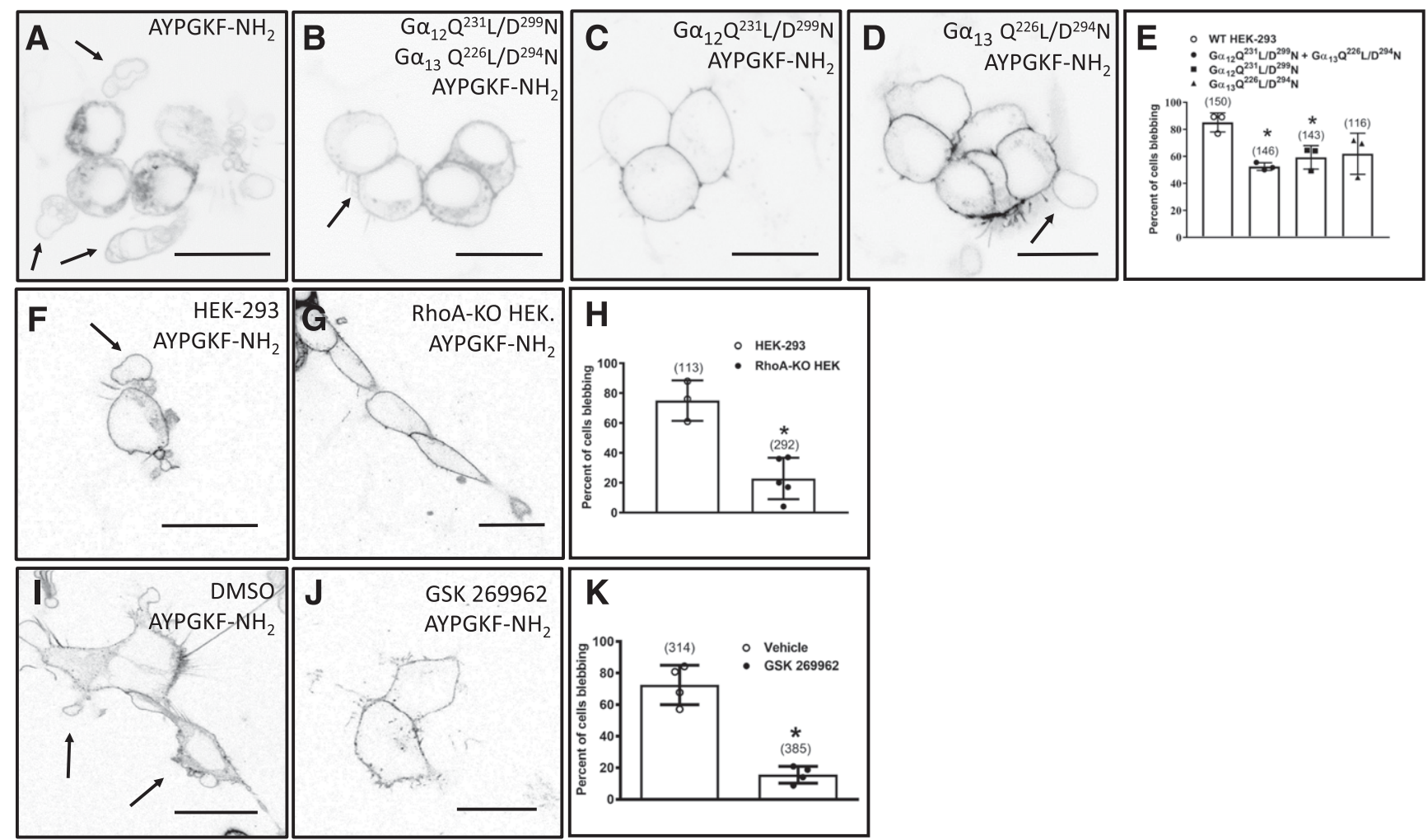

Fig. 6. PAR4-mediated cell shape change is $\mathrm{G} \alpha_{12^{-}}$, RhoA-, and ROCK-dependent. Confocal micrographs of HEK-293 cells stably expressing PAR4-YFP (shown in black) either alone (A) or transiently transfected with $0.5 \mu \mathrm{g}$ each of $\mathrm{G} \alpha_{12} \mathrm{Q}^{231} \mathrm{~L} / \mathrm{D}^{299} \mathrm{~N}$ and $\mathrm{G} \alpha_{13} \mathrm{Q}^{226} \mathrm{~L} / \mathrm{D}^{294} \mathrm{~N}(\mathrm{~B})$ or with $1 \mu \mathrm{g}$ of $\mathrm{G} \alpha_{12} \mathrm{Q}^{231} \mathrm{~L} / \mathrm{D}^{299} \mathrm{~N}(\mathrm{C})$ or $1 \mu \mathrm{g}$ of $\mathrm{G} \alpha_{13} \mathrm{Q}^{226} \mathrm{~L} / \mathrm{D}^{294} \mathrm{~N}(\mathrm{D})$ were treated with AYPGKF-NH $\mathrm{H}_{2}(30 \mu \mathrm{M})$ for 2 minutes and subsequently imaged by confocal microscopy. Arrows indicate bleb formation, and size bars are $20 \mu \mathrm{m}$. (E) Percentage of cells stably expressing PAR4-YFP alone or with transiently expressing G $\alpha_{12} \mathrm{Q}^{231} \mathrm{~L} / \mathrm{D}^{299} \mathrm{~N}$ and/or $\mathrm{G} \alpha_{13} \mathrm{Q}^{226} \mathrm{~L} / \mathrm{D}^{294} \mathrm{~N}$, displaying membrane blebbing in response to AYPGKF- $\mathrm{NH}_{2}(30 \mu \mathrm{M})$. Numbers above the bars indicate total number of cells scored. Data indicate mean \pm S.D. of three independent experiments, and asterisks indicate statistical difference; one-way ANOVA, $P>0.05$. Confocal micrographs of HEK-293 cells $(\mathrm{F})$ and RhoA-KO HEK (G) transiently transfected with $1 \mu \mathrm{g}$ of PAR4-YFP were stimulated with AYPGKF-NH ${ }_{2}(30 \mu M)$ for 2 minutes prior to imaging. Arrows indicate bleb formation; size bars are $20 \mu \mathrm{m}$. (H) Percentage of HEK-293 or RhoA-KO HEK transiently expressing PAR4-YFP and displaying membrane blebbing in response to AYPGKF- $\mathrm{NH}_{2}$ treatment $(30 \mu \mathrm{M})$. Data represent mean $\pm \mathrm{S.D}$. of four independent experiments, and asterisks show significant differences; unpaired $t$ test, $P<0.05$. Confocal micrographs of HEK-293 cells stably expressing PAR4-YFP and incubated with either DMSO (I) or GSK269962 (100 nM) for 1 hour $(\mathrm{J})$ prior to a 2-minute treatment with AYPGKF-NH ${ }_{2}(30 \mu \mathrm{M})$ and subsequent imaging. Arrows show bleb formation, and size bars are $20 \mu \mathrm{m}$. (K) Percentage of PAR4-YFP stably expressing HEK-293 cells displaying membrane bleb formation in the presence of AYPGKF-NH $\mathrm{NH}_{2}(30 \mu \mathrm{M})$ with DMSO (vehicle) or GSK26992 treatment Data represent mean \pm S.D. of four independent experiments, and asterisks show significant differences; paired $t$ test, $P<0.05$. WT, wild-type. 
induced an inhibition of DMB-forskolin-mediated cAMP production. $\mathrm{G} \alpha_{\mathrm{i}}$-coupled inhibition of cAMP production downstream of $\alpha_{2 \mathrm{~A}}$ receptor activation was abolished by PTX treatment (Supplemental Fig. 2, B and C). Taken together, these data indicate that PTX was indeed able to inhibit $\mathrm{G} \alpha_{\mathrm{i}}$ signaling as expected and that the lack in inhibition of PAR4-mediated blebbing in PTX-treated cells indicates that $\mathrm{G} \alpha_{\mathrm{i}}$-mediated signaling is not involved in this response.

PAR4-Mediated Cell Shape Change Is RhoA- and ROCK-Dependent. Having ruled out $\mathrm{G} \alpha_{\mathrm{q} / 11}$ and $\mathrm{G} \alpha_{\mathrm{i}}$ as mediators of PAR4-activated membrane blebbing, we sought to explore the involvement of other G-proteins. $\mathrm{G} \alpha_{12 / 13}$ proteins are known to activate the small G-protein RhoA. RhoA has been implicated in actin cytoskeletal rearrangements mediated by other GPCRs, and thus, we tested its role in this pathway. To explore a role for $\mathrm{G} \alpha_{12 / 13}$ in PAR4 signaling, we employed the use of two dominant negative constructs: $\mathrm{G} \alpha_{12} \mathrm{Q}^{231} \mathrm{~L} / \mathrm{D}^{299} \mathrm{~N}$ and $\mathrm{G} \alpha_{13} \mathrm{Q}^{226} \mathrm{~L} / \mathrm{D}^{294} \mathrm{~N}$. HEK-293 cells expressing PAR4 (Fig. 6A) were transiently transfected with $\mathrm{G} \alpha{ }_{12} \mathrm{Q}^{231} \mathrm{~L} / \mathrm{D}^{299} \mathrm{~N}$ alone (Fig. 6C), G $\alpha_{13} \mathrm{Q}^{226} \mathrm{~L} / \mathrm{D}^{294} \mathrm{~N}$ alone (Fig. 6D), or with both dominant negative constructs (Fig. 6B) and were imaged by confocal microscopy subsequent to AYPGKF-NH ${ }_{2}$ treatment. As before, we observed blebbing in PAR4-expressing cells $(85.10 \% \pm 7.08 \%)$, which was significantly reduced in cells expressing either $\mathrm{G} \alpha_{12} \mathrm{Q}^{231} \mathrm{~L} / \mathrm{D}^{299} \mathrm{~N}(52.45 \% \pm 2.83 \%)$ or $\mathrm{G} \alpha_{12} \mathrm{Q}^{231} \mathrm{~L} / \mathrm{D}^{299} \mathrm{~N}$ and $\mathrm{G} \alpha_{13} \mathrm{Q}^{226} \mathrm{~L} / \mathrm{D}^{294} \mathrm{~N}(59.31 \% \pm 8.66 \%)$ (Fig. 6E). However, expression of just $\mathrm{G} \alpha_{13} \mathrm{Q}^{226} \mathrm{~L} / \mathrm{D}^{294} \mathrm{~N}$ did not significantly the number of cells blebbing in response to AYPGKF-NH $\mathrm{NH}_{2}(61.93 \% \pm 15.19 \%)$. These data support a model whereby PAR4 couples to $\mathrm{G} \alpha_{12}$ to elicit blebbing responses.

Since RhoA can be activated by $\mathrm{G} \alpha_{12}$ (Siehler, 2009), and since RhoA is also well established as a regulator of actin cytoskeleton rearrangements (Barnes et al., 2005; Aoki et al., 2016), we examined whether PAR4-mediated blebbing was dependent on RhoA and Rho-associated kinase (ROCK). We used CRISPR/Cas9 targeting to explore this signaling pathway by creating a RhoA knockout HEK-293 cell line (RhoA-KO HEK). RhoA-KO HEK cells and control HEK-293 cells were transiently transfected with PAR4-YFP, stimulated with AYPGKF-NH $\mathrm{N}_{2}(30 \mu \mathrm{M})$, and imaged by confocal microscopy (Fig. 6, F and G). In total, $75 \% \pm 13.53 \%$ of control HEK-293 cells expressing PAR4-YFP and treated with AYPGKF-NH displayed membrane blebbing, whereas RhoA-KO HEK expressing PAR4-YFP show significantly fewer cells with blebs in response to agonist $(22.8 \% \pm 13.88 \%)$ (Fig. $6 \mathrm{H}$ ). To further interrogate this pathway, we employed the ROCK inhibitor GSK269962. Treatment of PAR4-YFP-expressing HEK-293 cells with the ROCK-specific inhibitor GSK269962 (Stavenger et al., 2007) significantly reduced the number of blebbing cells (Fig. 6, I and J). In total, $72.53 \% \pm 12.48 \%$ of DMSO vehicle control-treated cells displayed blebbing, whereas only $15.6 \% \pm 5.37 \%$ of cells treated with GSK269962 (100 nM) displayed bleb formation in response to AYPGKF-NH $\mathrm{N}_{2}(30 \mu \mathrm{M}$; Fig. 6K). Taken together, these data indicate that stimulation of PAR4-YFP elicits cell shape changes that are blocked by blebbistatin and by the ROCK inhibitor GSK269962. Further, these cell shape changes are significantly reduced in the presence of dominant negative $\mathrm{G} \alpha_{12}$ protein and do not occur in cells that do not express RhoA protein. Overall, these data suggest that PAR4 causes membrane blebbing through a $\mathrm{G}_{122^{-}}$, RhoA-, and ROCKdependent pathway.
To confirm that these cellular responses can also be recapitulated by a physiologic PAR4 agonist, we tested the ability of thrombin to elicit similar cell shape changes. Since thrombin can also activate PAR1, which is endogenously expressed in HEK-293 cells, we conducted these experiments in PAR1 knockout HEK-293 cells (PAR1-KO HEK) (Mihara et al., 2016) stably expressing PAR4-YFP (PAR1-KO-HEK-PAR4-YFP). PAR1-KO-HEK-PAR4-YFP cells were treated with $3 \mathrm{U} / \mathrm{ml}$ thrombin and visualized by confocal microscopy. Treatment of cells with thrombin caused cell shape changes similar to what was observed in HEK-293-

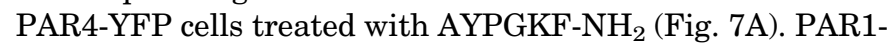
KO-HEK-PAR4-YFP cells were then treated with blebbistatin prior to thrombin stimulation (Fig. 7B). Blebbistatin significantly reduced the number of PAR1-KO-HEK-PAR4-YFP cells displaying membrane blebs from $68.3 \% \pm 8.08 \%$ to $11.67 \% \pm$ $10.02 \%$ (Fig. 7D). Finally, PAR1-KO-HEK-PAR4-YFP cells were treated with GSK269962 prior to stimulation with thrombin (Fig. 7C). GSK269962 (100 nM) significantly reduced the number of cells that displayed blebbing in response to thrombin stimulation $(9.33 \% \pm 7.50 \%)$ (Fig. 7D). Together, these data indicate that cell blebbing is triggered not only by the synthetic PAR4-activating peptide AYPGKF-NH but also by one of the endogenous activators of PAR4, thrombin, in a PAR1-null background. Cell shape changes mediated by thrombin activation of PAR4 are also RhoAand ROCK-dependent.

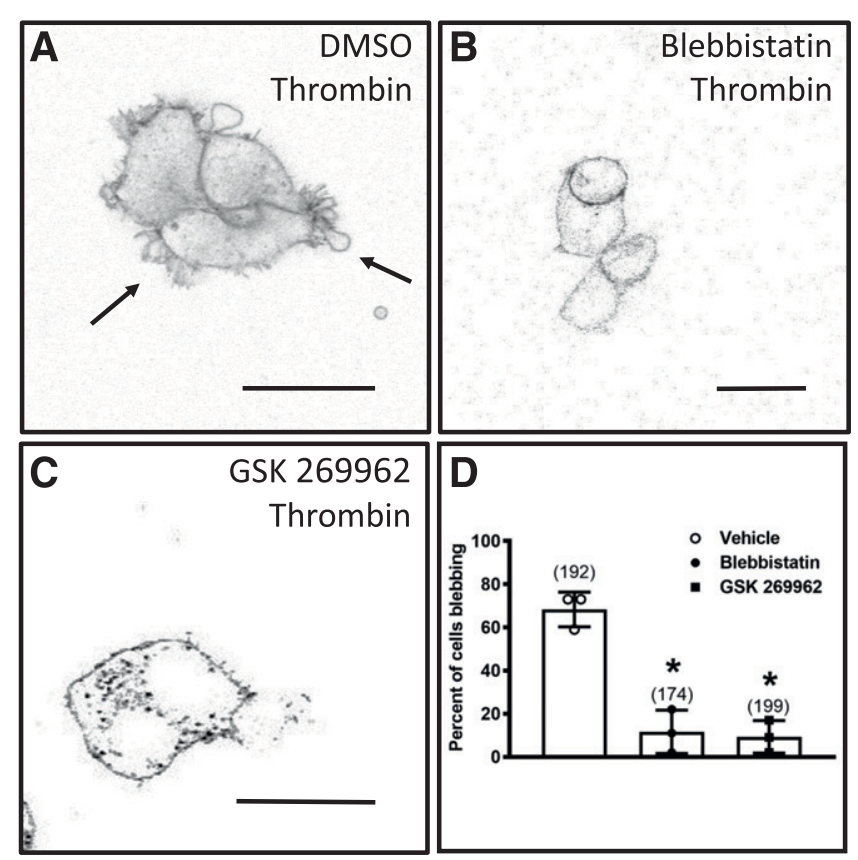

Fig. 7. Thrombin-induced PAR4-mediated cell shape change is ROCKdependent. Confocal micrographs showing control HEK-293 cells with CRISPR/Cas9 deletion of PAR1 (PAR1-KO-HEK-293) and stably expressing PAR4 (PAR1-KO-PAR4-YFP-HEK-293) incubated in either DMSO (A) or blebbistatin $(10 \mu \mathrm{M})$ for 15 minutes (B) or GSK269962 $(100 \mathrm{nM})$ for 1 hour (C) prior to a 2-minute treatment with thrombin $(3 \mathrm{U} / \mathrm{ml})$ and subsequent imaging. Arrows show bleb formation; size bars are $20 \mu \mathrm{m}$. (D) Percentage of PAR1-KO-PAR4-YFP-HEK-293 cells showing membrane blebbing in response to thrombin treatment $(3 \mathrm{U} / \mathrm{ml})$ in the presence of either DMSO (vehicle), blebbistatin $(10 \mu \mathrm{M})$, or GSK269962 (100 nM). Numbers above the bars indicate the total number of cells scored. Data represent mean \pm S.D. of four independent experiements, and asterisks show significant differences; one-way ANOVA, $P<0.05$. 
PAR4-Mediated Cell Shape Change Is $\beta$-ArrestinDependent. Since the nonblebbing dRS-PAR4-YFP-expressing cells are also deficient in $\beta$-arrestin recruitment (Ramachandran et al., 2017), we next examined the contribution of $\beta$-arrestinmediated signaling in PAR4-dependent cell membrane blebbing. To elucidate a role for $\beta$-arrestins in PAR4-mediated cell shape change, a $\beta$-arrestin- 1 and 2 double knockout cell line ( $\beta$-arrestin-1/2 KO HEK) was created using CRISPR/ Cas9 targeting. $\beta$-Arrestin- $1 / 2$ KO HEK cells transiently expressing PAR4-YFP ( $\beta$-arrestin-1/2 KO HEK-PAR4-YFP) were treated with AYPGKF- $\mathrm{NH}_{2}(30 \mu \mathrm{M})$ and visualized by confocal microscopy (Fig. 8, A and B). A modest but significant reduction in the number of blebbing $\beta$-arrestin-1/2 KO HEK-PAR4-YFP $(46 \% \pm 18.34 \%)$ was observed when compared with control HEK-293 cells transiently expressing PAR4-YFP $(80.8 \% \pm 6.10 \%)$ (Fig. $8 \mathrm{C}$ ). These results indicate that PAR4-elicited membrane blebbing is, in part, $\beta$-arrestin-dependent.

Since recent reports have questioned whether $\beta$-arrestinmediated signaling can occur in the absence of G-protein activation (Grundmann et al., 2018), we sought to understand this requirement in the context of PAR4 signaling. Even though $\mathrm{G} \alpha_{\mathrm{q} / 11}$ and $\mathrm{G} \alpha_{\mathrm{i}}$ recruitment was not implicated in PAR4-dependent membrane blebbing, we nevertheless examined the effect of blocking these pathways on $\beta$-arrestin- $1 / 2$ recruitment to PAR4. To this end, we blocked $\mathrm{G} \alpha_{\mathrm{q} / 11}$ with the inhibitor YM254890 (100 nM) and blocked $\mathrm{G} \alpha_{\mathrm{i}}$ with pertussis toxin $(100 \mathrm{nM})$ and examined their ability to disrupt $\beta$-arrestin recruitment to PAR4-YFP. We employed a BRET assay to monitor interaction between PAR4-YFP and $\beta$-arrestin-1-Rluc or $\beta$-arrestin-2-Rluc in response to 30,100 , and $300 \mu \mathrm{M}$ AYPGKF-NH $\mathrm{N}_{2}$. Treatment of cells with YM254890 did not significantly reduce recruitment of $\beta$-arrestin- 1 or $\beta$-arrestin- 2 recruitment to PAR4 at $30 \mu \mathrm{M}$ or $100 \mu \mathrm{M}$ concentrations of AYPGKF- $\mathrm{NH}_{2}$ but did significanctly reduce recruitment of both $\beta$-arrestin- 1 and 2 in the $300 \mu \mathrm{M}$
AYPGKF-NH $\mathrm{N}_{2}$ (Fig. 8D) treatment condition. Treatment of cells with pertussis toxin had no effect on $\beta$-arrestin recruitment at any of the concentrations tested (Fig. 8E).

Finally, we tested a role for $\mathrm{G}_{\beta \gamma}$ signaling in PAR4-mediated cell shape change using the $\mathrm{G}_{\beta \gamma}$ inhibitor gallein. HEK-293 cells stably expressing PAR4-YFP were incubated with gallein $(10 \mu \mathrm{M})$ or vehicle control (DMSO) prior to treatment with AYPGKF-NH $\mathrm{N}_{2}(30 \mu \mathrm{M}$; Fig. 9, A and B). Cells treated with gallein did not show a significant reduction in membrane blebbing compared with DMSO-treated cells $(61.75 \% \pm$ $9.75 \%$ and $85.28 \% \pm 10.56 \%$, respectively) (Fig. 9C). Cells expressing PAR4-YFP and either $\beta$-arrestin-1-Rluc or -2-Rluc incubated with gallein prior to treatment with AYPGKF- $\mathrm{NH}_{2}$ at 30,100 , and $300 \mu \mathrm{M}$ also retained their ability to recruit $\beta$-arrestin- 1 and 2 at all concentrations of AYPGKF- $\mathrm{NH}_{2}$ (Fig. 9D). Taken together, these data show that PAR4mediated cell shape changes are independent of $\mathrm{G} \alpha_{\mathrm{q} / 11}$, $\mathrm{G} \alpha_{\mathrm{I}}$, and $\mathrm{G}_{\beta \gamma}$. Further inhibition of $\mathrm{G} \alpha_{\mathrm{i}}$ and $\mathrm{G}_{\beta \gamma}$ individually does not impede $\beta$-arrestin recruitment to PAR4, whereas $\mathrm{G} \alpha_{\mathrm{q} / 11}$ inhibition partially reduces $\beta$-arrestin recruitment to PAR4.

PAR4 Activation in Rat Primary Aortic Vascular Smooth Muscle Cells Leads to Cell Shape Changes. To examine whether PAR4 activation triggers cell blebbing in cells that endogenously express PAR4, we turned to the rat vascular smooth muscle cells. Vascular smooth muscle cells (VSMC) are reported to express PAR4 (Bretschneider et al., 2001; Dangwal et al., 2011), and in our hands, rat aortic smooth muscle cells from both Wistar Kyoto (WKY) and spontaneously hypertensive (SHR) rats expressed PAR4 mRNA (Fig. 10I). We labeled the smooth muscle cell membrane with cell mask (ThermoFisher) and stimulated with AYPGKF-NH ${ }_{2}(30 \mu \mathrm{M})$. Both WKY (Fig. 10A) and SHR (Fig. 10E) VSMC displayed cell shape changes resembling membrane blebs in response to PAR4 agonist treatment. To establish whether the signaling mechanism for these cell

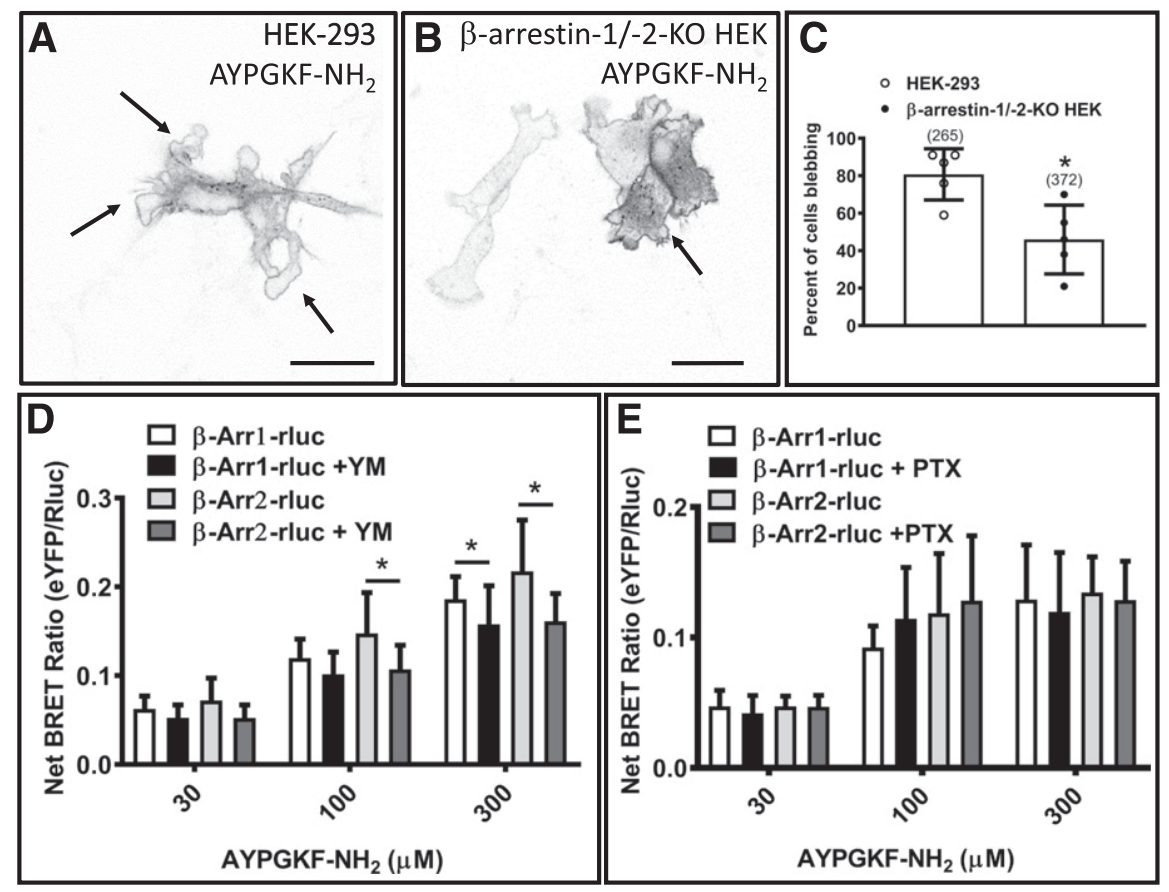

Fig. 8. PAR4-mediated cell shape change is $\beta$-arrestin-dependent. Confocal micrographs of HEK-293 cells (A) or $\beta$-arrestin-1/2-KO HEK that were transiently transfected with $1 \mu \mathrm{g}$ of PAR4-YFP (B) and were stimulated in AYPGKF-NH $(30 \mu \mathrm{M})$ for 2 minutes prior to confocal imaging. Arrows indicate bleb formation, and size bars are $20 \mu \mathrm{m}$. (C) Percentage of HEK-293 cells or $\beta$-arrestin1/2-KO-HEK-293 transiently transfected with $1 \mu \mathrm{g}$ of PAR4-YFP, displaying membrane blebbing in response to AYPGKF-NH ${ }_{2}(30 \mu \mathrm{M})$ treatment. Data indicate mean \pm S.D. of four independent experiments, and asterisks show significant differences; unpaired $t$ test, $P<0.05$. HEK-293 cells, transiently transfected with $1 \mu \mathrm{g}$ of PAR4-YFP and $0.1 \mu \mathrm{g}$ of either $\beta$-arrestin-1-Rluc or $0.1 \mu \mathrm{g}$ of $\beta$-arrestin-2-Rluc were incubated in DMSO or YM254890 $(100 \mathrm{nM})$ (D) for 20 minutes or PTX $(100 \mathrm{ng} / \mathrm{ml})$ for 18 hours (E) prior to testing in the BRET assay. Data represent mean \pm S.D. of four independent experiments, and asterisks shows significant differences; two-way ANOVA, Sidak's multiple comparisons test, $P<0.05$. 

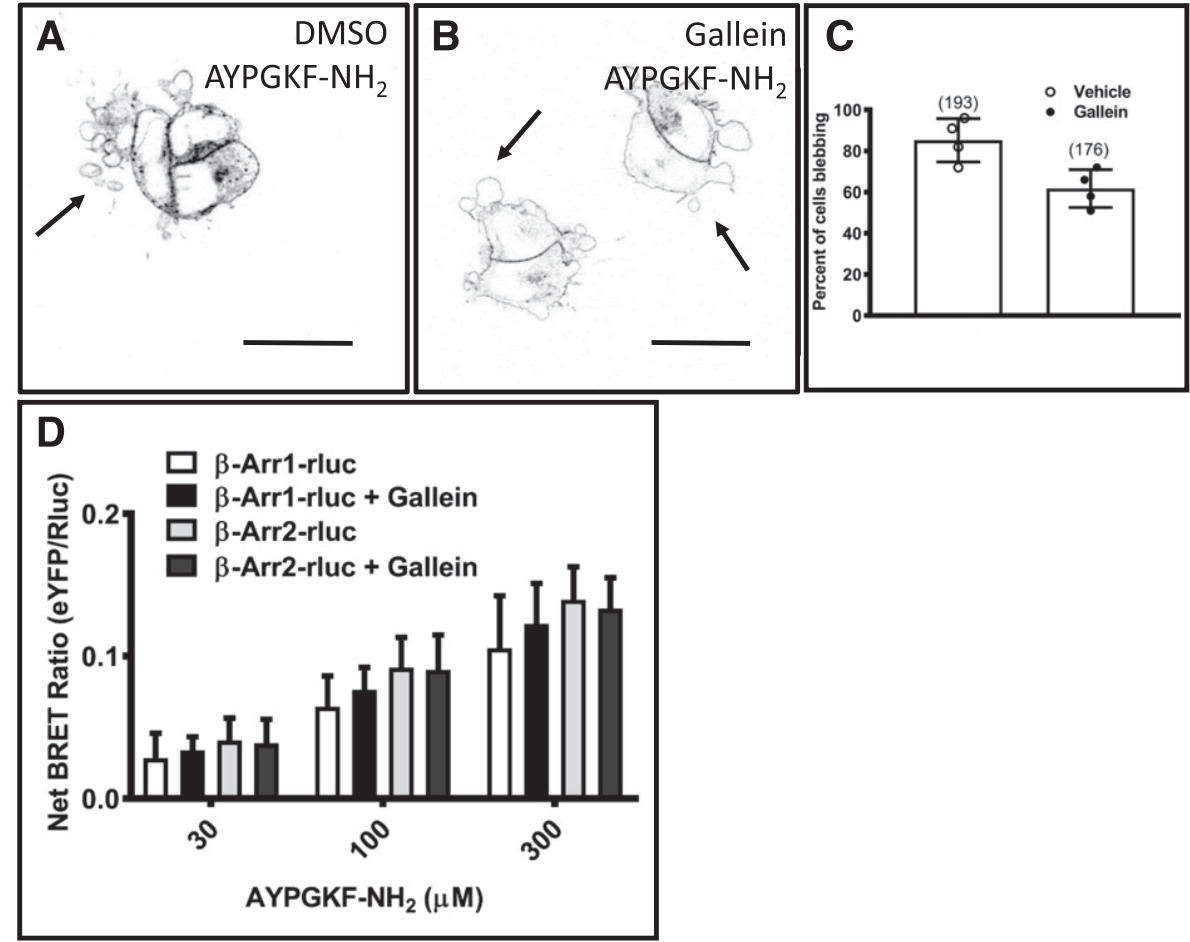

shape changes was the same in both VSMC and HEK-293 cells, we pretreated VSMC with blebbistatin or ROCK inhibitor (GSK269962) prior to activating PAR4 with AYPGKF-NH $(30 \mu \mathrm{M})$. In total, $67.25 \% \pm 13.25 \%$ of WKY cells display cell shape changes in response to PAR4 agonist (Fig. 10, A and D), which was significantly reduced with blebbistatin treatment
$(9.0 \% \pm 6.28 \%)($ Fig. 10, B and D) or upon treatment with GSK269962 (6.5\% $\pm 0.57 \%)$ (Fig. 10, C and D). Consistent with these findings, $65.96 \% \pm 10.12 \%$ of SHR cells also displayed blebbing after PAR4 activation (Fig. 10E), and these responses were significantly reduced with blebbistatin $(14.5 \% \pm 3.7 \%)$ (Fig. 10, F and H) and with GSK269962 (15.7\% $\pm 5.8 \%)$
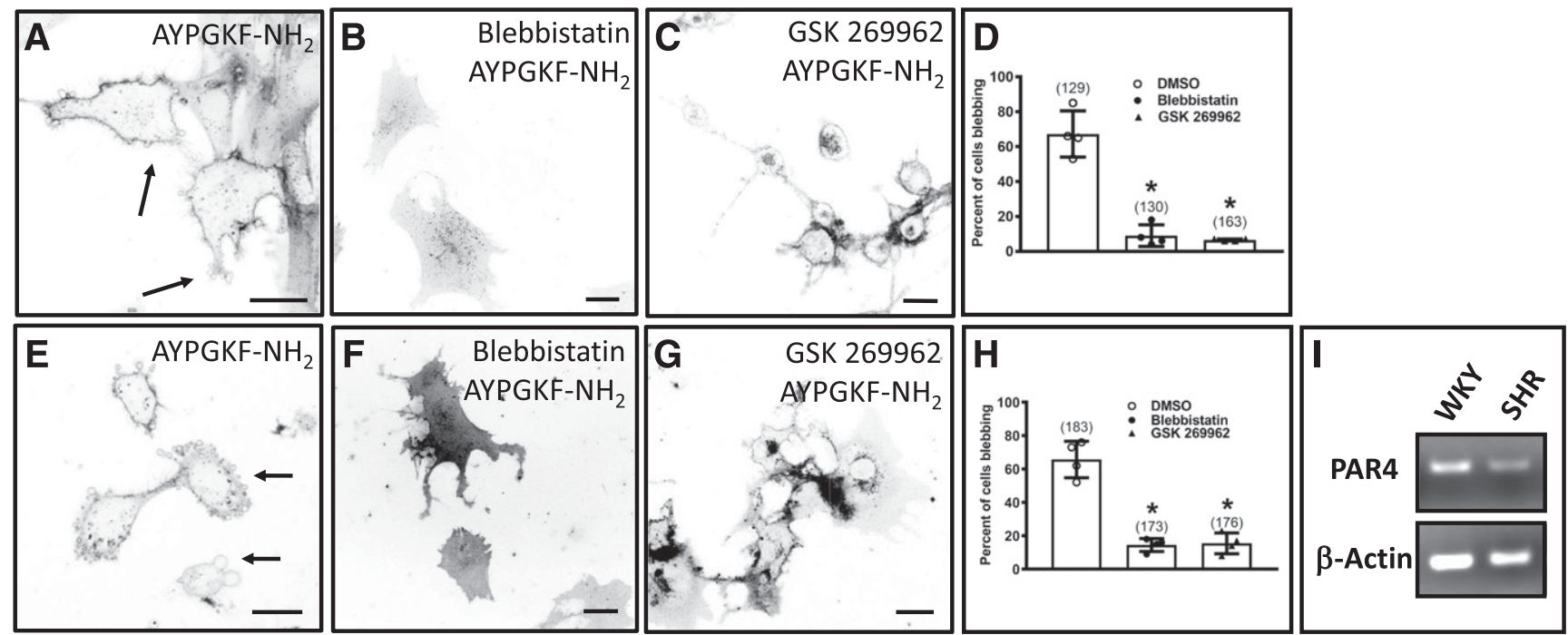

Fig. 10. PAR4 mediates membrane blebs in vascular smooth muscle cells. Primary cultured vascular smooth muscle cells derived from WKY (A-D) or from SHR (E-H) rats were preincubated for 10 minutes in cell mask to stain the plasma membrane (shown in black); cells were then treated with AYPGFK-NH $\mathrm{N}_{2}(30 \mu \mathrm{M})$ and imaged by confocal microscopy. WKY cells and SHR cells were preincubated with DMSO (A and E) or with blebbistatin $(10 \mu \mathrm{M})$ for 15 minutes (B and F) or with GSK269962 (100 nM) for 1 hour (C and G) prior to stimulation with AYPGFK-NH ${ }_{2}$; arrows show bleb formation, and size bars are $20 \mu \mathrm{m}$. (D) Percentage of WKY cells displaying membrane blebbing in response to AYPGFK-NH $(30 \mu \mathrm{M})$ in the presence of either blebbistatin $(10 \mu \mathrm{M})$ or GSK269962 $(100 \mathrm{nM})$. Numbers above the bars indicate the total number of cells scored. Data indicate mean \pm S.D. of four independent experiments, and asterisks show significant differences; Kruskal-Wallis test, Dunn's multiple comparison test, $P<0.05$. (H) Percentage of SHR cells displaying membrane blebbing in response to AYPGFK- $\mathrm{NH}_{2}(30 \mu \mathrm{M})$ in the presence of either blebbistatin or GSK269962. Numbers above the bars indicate total number of cells scored. Data indicate mean \pm S.D. of four independent experiments, and asterisks show significant differences; Kruskal-Wallis test, Dunn's multiple comparison test, $P<0.05$. (I) Gel image representing PCR product generated by use of PAR4-specific primers or $\beta$-actin-specific primers in WKY and SHR cells. 
treatment (Fig. 10, $\mathrm{G}$ and $\mathrm{H}$ ). These data indicate that endogenous PAR4 activation elicits membrane blebbing in VSMC that is ROCK-dependent, in keeping with our findings in the HEK-293 cells exogenously expressing PAR4.

\section{Discussion}

We have demonstrated that activation of PAR4 with thrombin or the synthetic PAR4 activating peptide AYPGKF-NH $\mathrm{N}_{2}$ causes a rapid cell shape change response in PAR4-transfected HEK-293 cells or in vascular smooth muscle cells that endogenously express PAR4. Cell shape changes are pharmacologically inhibited by blebbistatin and are consistent with membrane bleb formation. We observed membrane blebs that formed within 2-5 minutes of agonist treatment and lasted for up to 30 minutes. Membrane blebbing could be pharmacologically inhibited by the ROCK inhibitor GSK269962 or through CRISPR/Cas9-mediated knockout of RhoA. CRISPR/Cas9 knockout of $\beta$-arrestin-1 and 2 partially abolished PAR4-dependent membrane blebbing, as did overexpression of a dominant negative $\mathrm{G} \alpha_{12}$ protein. We further found PAR4-dependent membrane bleb formation to be independent of $\mathrm{G} \alpha_{\mathrm{q} / 11}, \mathrm{G} \alpha_{\mathrm{i}}, \mathrm{G}_{\beta \gamma}$, and PKC (Fig. 11). Overall, our data suggest that $\mathrm{G} \alpha_{12} /$ /RhoA-dependent membrane blebbing occurs downstream of PAR4 activation and $\beta$-arrestin recruitment.

Nonapoptotic cell membrane blebbing plays an important role in various physiologic and pathologlical processes. Various stimuli have been reported to trigger bleb formation, leading to cellular responses including enhanced cell motility, invasion, cell locomotion, and regulation of cell polarity in embryonic development (Charras and Paluch, 2008; Fackler and Grosse, 2008; Ikenouchi and Aoki, 2017). Blebbing is also an important regulator of wound healing, immune cell maturation, and inflammation. In this context, the PAR family of GPCRs is well established as critical regulators of the innate immune response to injury and infection. PARs also elicit cellular responses that allow coagulation cascade enzymes such as thrombin and other serine proteinases to regulate various cellular functions. PAR1 and PAR4 serve as the receptors for thrombin on human platelets, although these receptors regulate different aspects of platelet activation (Coughlin, 1999; Kahn et al., 1999; Ma et al., 2005; Holinstat et al., 2006; Voss et al., 2007). PAR4 is described as the lowaffinity thrombin receptor on human platelets. This lower affinity stems from the lack of a hirudin-like binding site for thrombin on PAR4 that is present on PAR1. In platelets, PAR4 activation typically requires a much higher concentration of thrombin to be present, and PAR4 activation typically results in more sustained calcium signaling compared with PAR1dependent signaling (Covic et al., 2000; Shapiro et al., 2000).

Both PAR1 and PAR4 activation triggers platelet aggregation, with PAR4 signaling critical for full platelet spreading and formation of stable aggregates. In rodents, PAR4 serves as the sole thrombin receptor in platelets (Sambrano et al., 2001). It has been previously shown in $\mathrm{G} \alpha_{\mathrm{q} / 11}$ knockout mice that a thrombin-activated $\mathrm{G} \alpha_{\mathrm{q} / 11}$-mediated calcium response is necessary for platelet aggregation (Offermanns et al., 1997). However, platelets from the mouse $\mathrm{G} \alpha_{\mathrm{q} / 11}$ knockout retained the ability to change shape in response to thrombin stimulation. Similar findings were reported in platelets treated with a smallmolecule $\mathrm{G} \alpha_{\mathrm{q} / 11}$ antagonist, UBO-QIC, showing that platelet aggregation was inhibited without affecting shape change responses (Inamdar et al., 2015). Consistent with these findings, we have observed a cell shape change specific to PAR4 activation that is $\mathrm{G} \alpha_{\mathrm{q} / 11}$-independent and a RhoA-mediated phenomenon. Recent evidence suggests that PAR4 plays an important role in promoting platelet granule release and platelet-leukocyte interactions (Rigg et al., 2019), responses which also rely on a RhoA-mediated cytoskeletal rearrangement (Moers et al., 2003; Aslan and Mccarty, 2013). These findings raise the interesting possibility that different signaling pathways may underlie PAR4 regulation of distinct aspects of platelet activation, and further study is required to fully elucidate the role of different signaling cascades in

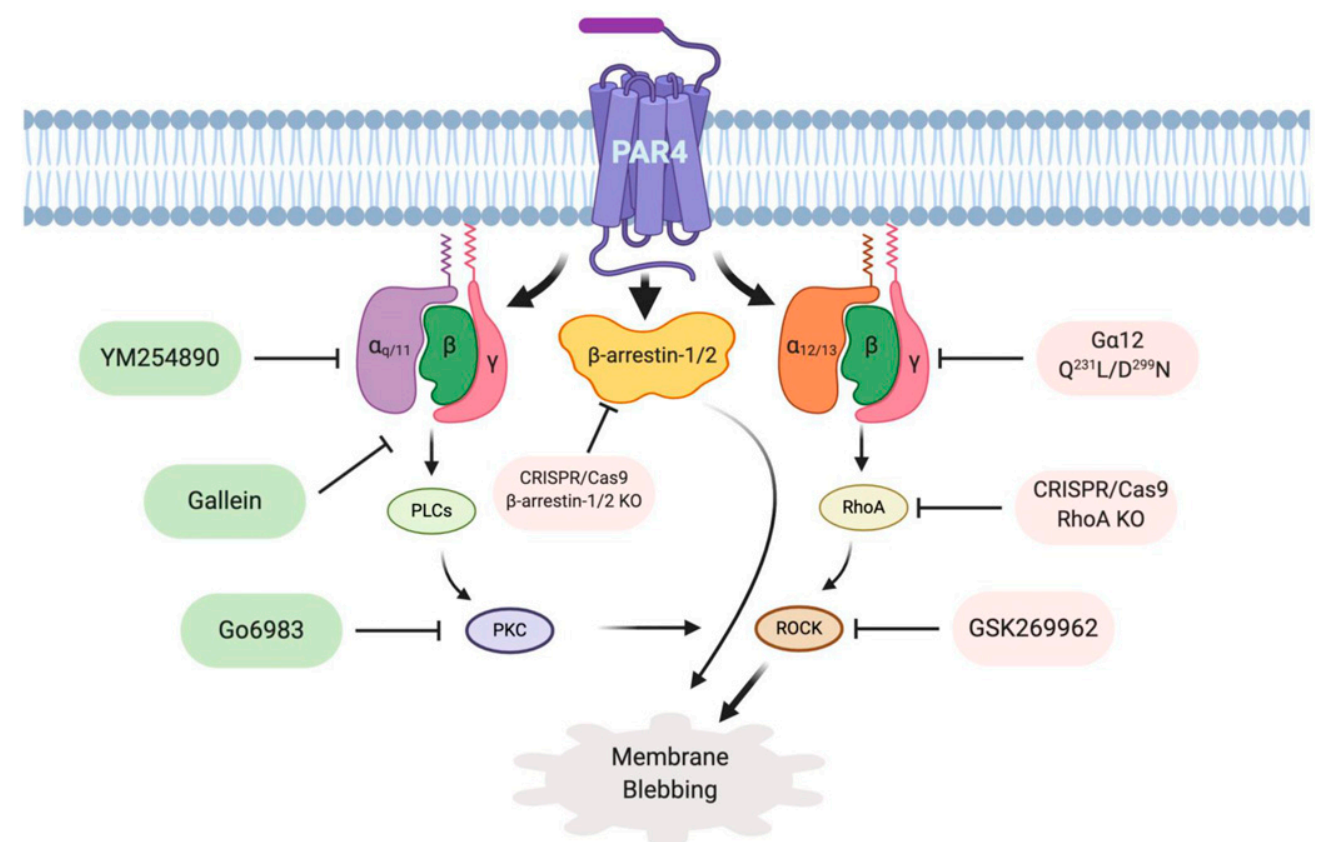

Fig. 11. PAR4 signaling pathways leading to membrane blebbing. Schema shows known PAR4 signaling partners that were interrogated pharmacologically or genetically for their potential contribution to membrane blebbing. We find that agonist activation of PAR4 induces membrane blebbing that is independent of $\mathrm{G} \alpha_{\mathrm{q} / 11}$ signaling but is dependent on $\beta$-arrestin, $\mathrm{G} \alpha_{12}$, and RhoA/ROCK. Pharmacological inhibitors that blocked PAR4-induced membrane blebbing are shown in red, and inhibitors that had no effect on membrane blebbing are shown in green. Biorender.com 
mediating PAR4 responses in platelets. Our studies suggest that in HEK-293 cells, the $\mathrm{G} \alpha_{\mathrm{q} / 11}$-coupled pathway and the RhoA pathway, which in this instance we show is downstream of $\mathrm{G} \alpha_{12}$ coupling, can act independently and therefore may be independent targets for pharmacological manipulation.

PAR4 expression has also been reported in other cell types involved in the response to injury, including endothelial cells and smooth muscle cells (Bretschneider et al., 2001; Hamilton et al., 2001; Fujiwara et al., 2005; Ritchie et al., 2007). Here, we demonstrate that agonist stimulation of endogenous PAR4 in vascular smooth muscle cells leads to membrane blebbing. This finding is consistent with a previous study that showed that another GPCR, Angiotensin II receptor type 1, mediates membrane blebbing by a RhoA-dependent mechanism in a vascular smooth muscle cell line (Godin and Ferguson, 2010). RhoA is well established as a mediator of changes in the plasma membrane actin cytoskeleton and in regulating GPCR-mediated cell shape change (Barnes et al., 2005; Godin and Ferguson, 2010; Aoki et al., 2016). Our findings add PAR4-dependent signaling to the cell surface signaling molecules that can trigger this pathway.

$\beta$-Arrestins are now well established as important molecular scaffolds linking GPCRs not only to molecular endocytic partners to facilitate receptor endocytosis but also to second messenger signal cascades (Ferguson, 2001; Magalhaes et al., 2012). For example, $\beta$-arrestins link GPCRs to $\mathrm{p} 44 / 42$ mitogenactivated protein kinase signaling from the endosome (Luttrell et al., 2001; Luttrell and Lefkowitz, 2002). PAR4 couples to both $\beta$-arrestin- 1 and $\beta$-arrestin-2, and PAR4-mediated phosphorylation of AKT in platelets is $\beta$-arrestin-2-dependent (Li et al., 2011) activation. Recently, it has been shown that pepducin-mediated, $\beta$-arrestin-dependent activation of RhoA/ROCK pathway mediated by $\beta 2$-adrenergic receptor in cardiomyocytes is cardio-protective, highlighting the importance of $\beta$-arrestin signaling and also showing a link between $\beta$-arrestin and RhoA signaling molecules (Grisanti et al., 2018). A previous study has also shown that $\beta$-arrestins are an integral part of focal adhesion dynamics and regulate clathrin and microtubuledependent focal adhesion disassembly independently of GPCR signaling (Cleghorn et al., 2015). In our hands, there appears to be a role for $\beta$-arrestins in mediating membrane blebbing downstream of PAR4; however, additional GPCR-independent roles of $\beta$-arrestin on cytoskeletal dynamics cannot be ruled out. Our data here suggest that GPCR-mediated membrane blebbing and actin cytoskeletal rearrangements are predominantly G-protein-dependent and partially dependent on $\beta$-arrestins. Consistent with previous studies, we show that membrane blebbing is RhoA-dependent (Barnes et al., 2005; Godin and Ferguson, 2010); however, we find that PAR4 engages this signaling pathway through $\mathrm{G} \alpha_{12}$ protein and $\operatorname{not} \mathrm{G} \alpha_{\mathrm{q} / 11}$.

In conclusion, we have uncovered a PAR4-mediated cellular response that is independent of $\mathrm{G} \alpha_{\mathrm{q} / 11}$ coupling and occurs downstream of RhoA activation and $\beta$-arrestin signaling (Fig. 11). These data provide further evidence for pathway-selective signaling responses through PAR4 and may guide future development of PAR4 targeting strategies.

\section{Acknowledgments}

We would like to thank Dr. Michel Bouvier (U. de Montreal) for sharing the Rluc-tagged $\beta$-arrestin-1 ( $\beta$-arrestin-1-rluc) or $\beta$-arrestin-2 $(\beta$-arrestin-2-rluc) constructs, Dr. Feng Zhang (MIT) for providing the pSpCas9(BB)-2A-GFP (PX458) (plasmid \# 48138; Addgene), and Dr. Peter Chidiac (UWO) for providing pGloSensor-22F cAMP Plasmid.

\section{Authorship Contributions}

Participated in research design: Vanderboor, Thibeault, Nixon, Gros, Kramer, Ramachandran.

Conducted experiments: Vanderboor, Thibeault, Nixon, Ramachandran. Contributed new reagents or analytic tools: Vanderboor, Thibeault, Nixon, Gros, Kramer, Ramachandran.

Performed data analysis: Vanderboor, Thibeault, Nixon, Kramer, Ramachandran.

Wrote or contributed to the writing of the manuscript: Vanderboor, Thibeault, Ramachandran.

\section{References}

Anthony DF, Sin YY, Vadrevu S, Advant N, Day JP, Byrne AM, Lynch MJ, Milligan G, Houslay MD, and Baillie GS (2011) $\beta$-Arrestin 1 inhibits the GTPase-activating protein function of ARHGAP21, promoting activation of RhoA following angiotensin II type 1A receptor stimulation. Mol Cell Biol 31:1066-1075.

Aoki K, Maeda F, Nagasako T, Mochizuki Y, Uchida S, and Ikenouchi J (2016) A RhoA and Rnd3 cycle regulates actin reassembly during membrane blebbing. Proc Natl Acad Sci USA 113:E1863-E1871.

Aslan JE and McCarty OJT (2013) Rho GTPases in platelet function. J Thromb Haemost 11:35-46.

Barnes WG, Reiter E, Violin JD, Ren XR, Milligan G, and Lefkowitz RJ (2005) betaArrestin 1 and Galphaq/11 coordinately activate RhoA and stress fiber formation following receptor stimulation. J Biol Chem 280:8041-8050.

Bretschneider E, Kaufmann R, Braun M, Nowak G, Glusa E, and Schrör K (2001) Evidence for functionally active protease-activated receptor-4 (PAR-4) in human vascular smooth muscle cells. $\mathrm{Br} J$ Pharmacol 132:1441-1446.

Charras G and Paluch E (2008) Blebs lead the way: how to migrate without lamellipodia. Nat Rev Mol Cell Biol 9:730-736.

Charras GT (2008) A short history of blebbing. J Microsc 231:466-478.

Charras GT, Coughlin M, Mitchison TJ, and Mahadevan L (2008) Life and times of a cellular bleb. Biophys $J$ 94:1836-1853.

Chen P, Douglas SD, Meshki J, and Tuluc F (2012) Neurokinin 1 receptor mediates membrane blebbing and sheer stress-induced microparticle formation in HEK293 cells. PLoS One 7:e45322.

Cheung A, Dantzig JA, Hollingworth S, Baylor SM, Goldman YE, Mitchison TJ, and Straight AF (2002) A small-molecule inhibitor of skeletal muscle myosin II. Nat Cell Biol 4:83-88.

Cleghorn WM, Branch KM, Kook S, Arnette C, Bulus N, Zent R, Kaverina I, Gurevich EV, Weaver AM, and Gurevich VV (2015) Arrestins regulate cell spreading and motility via focal adhesion dynamics. Mol Biol Cell 26:622-635.

Cong L, Ran FA, Cox D, Lin S, Barretto R, Habib N, Hsu PD, Wu X, Jiang W, Marraffini LA, et al. (2013) Multiplex genome engineering using CRISPR/Cas systems. Science 339:819-823.

Coughlin SR (1999) How the protease thrombin talks to cells. Proc Natl Acad Sci USA 96:11023-11027.

Covic L, Gresser AL, and Kuliopulos A (2000) Biphasic kinetics of activation and signaling for PAR1 and PAR4 thrombin receptors in platelets. Biochemistry 39: 5458-5467.

Dale LB, Babwah AV, Bhattacharya M, Kelvin DJ, and Ferguson SS (2001) Spatial-temporal patterning of metabotropic glutamate receptor-mediated inositol 1,4,5-triphosphate, calcium, and protein kinase $\mathrm{C}$ oscillations: protein kinase C-dependent receptor phosphorylation is not required. $\mathrm{J} \mathrm{Biol}$ Chem 276:35900-35908.

Dangwal S, Rauch BH, Gensch T, Dai L, Bretschneider E, Vogelaar CF, Schrör K, and Rosenkranz AC (2011) High glucose enhances thrombin responses via protease-activated receptor-4 in human vascular smooth muscle cells. Arterioscler Thromb Vasc Biol 31:624-633.

Exton JH (1996) Regulation of phosphoinositide phospholipases by hormones, neurotransmitters, and other agonists linked to G proteins. Annu Rev Pharmacol Toxicol 36:481-509.

Fackler OT and Grosse R (2008) Cell motility through plasma membrane blebbing. $J$ Cell Biol 181:879-884.

Ferguson SS (2001) Evolving concepts in G protein-coupled receptor endocytosis: the role in receptor desensitization and signaling. Pharmacol Rev 53:1-24.

Ferguson SSG and Caron MG (2004) Green fluorescent protein-tagged $\beta$-Arrestin translocation as a measure of $\mathrm{G}$ protein-coupled receptor activation, in $G$ Protein Signaling: Methods and Protocols (Smrcka AV ed) pp 121-126, Humana Press, Totowa, NJ.

Fujiwara M, Jin E, Ghazizadeh M, and Kawanami O (2005) Activation of PAR4 induces a distinct actin fiber formation via p38 MAPK in human lung endothelial cells. J Histochem Cytochem 53:1121-1129.

Godin CM and Ferguson SSG (2010) The angiotensin II type 1 receptor induces membrane blebbing by coupling to Rho A, Rho kinase, and myosin light chain kinase. Mol Pharmacol 77:903-911.

Gong X, Didan Y, Lock JG, and Strömblad S (2018) KIF13A-regulated RhoB plasma membrane localization governs membrane blebbing and blebby amoeboid cell migration. EMBO $J$ 37:e98994.

Goupil E, Tassy D, Bourguet C, Quiniou C, Wisehart V, Pétrin D, Le Gouill C, Devost D, Zingg HH, Bouvier M, et al. (2010) A novel biased allosteric compound inhibitor of parturition selectively impedes the prostaglandin F2alpha-mediated Rho/ROCK signaling pathway. J Biol Chem 285:25624-25636. 
Grisanti LA, Thomas TP, Carter RL, de Lucia C, Gao E, Koch WJ, Benovic JL, and Tilley DG (2018) Pepducin-mediated cardioprotection via $\beta$-arrestin-biased $\beta 2$ adrenergic receptor-specific signaling. Theranostics 8:4664-4678.

Gros R, Ding Q, Chorazyczewski J, Pickering JG, Limbird LE, and Feldman RD (2006) Adenylyl cyclase isoform-selective regulation of vascular smooth muscle proliferation and cytoskeletal reorganization. Circ Res 99:845-852.

Grundmann M, Merten N, Malfacini D, Inoue A, Preis P, Simon K, Rüttiger N, Ziegler N, Benkel T, Schmitt NK, et al. (2018) Lack of beta-arrestin signaling in the absence of active G proteins. Nat Commun 9:341.

Gschwendt M, Dieterich S, Rennecke J, Kittstein W, Mueller HJ, and Johannes FJ (1996) Inhibition of protein kinase $\mathrm{C}$ mu by various inhibitors. Differentiation from protein kinase c isoenzymes. FEBS Lett 392:77-80.

Hagmann J, Burger MM, and Dagan D (1999) Regulation of plasma membrane blebbing by the cytoskeleton. J Cell Biochem 73:488-499.

Hamilton JR, Frauman AG, and Cocks TM (2001) Increased expression of proteaseactivated receptor-2 (PAR2) and PAR4 in human coronary artery by inflammatory stimuli unveils endothelium-dependent relaxations to PAR2 and PAR4 agonists. Circ Res 89:92-98.

Holinstat M, Voss B, Bilodeau ML, McLaughlin JN, Cleator J, and Hamm HE (2006 PAR4, but not PAR1, signals human platelet aggregation via $\mathrm{Ca} 2+$ mobilization and synergistic P2Y12 receptor activation. J Biol Chem 281:26665-26674.

Hsu PD, Scott DA, Weinstein JA, Ran FA, Konermann S, Agarwala V, Li Y, Fine EJ, Wu X, Shalem O, et al. (2013) DNA targeting specificity of RNA-guided Cas 9 nucleases. Nat Biotechnol 31:827-832.

Ikenouchi J and Aoki K (2017) Membrane bleb: a seesaw game of two small GTPases. Small GTPases 8:85-89.

Inamdar V, Patel A, Manne BK, Dangelmaier C, and Kunapuli SP (2015) Characterization of UBO-QIC as a G $\alpha$ q inhibitor in platelets. Platelets 26:771-778.

Kahn ML, Nakanishi-Matsui M, Shapiro MJ, Ishihara H, and Coughlin SR (1999) Protease-activated receptors 1 and 4 mediate activation of human platelets by thrombin. J Clin Invest 103:879-887.

Kim S, Jin J, and Kunapuli SP (2006) Relative contribution of G-protein-coupled pathways to protease-activated receptor-mediated Akt phosphorylation in platelets. Blood 107:947-954.

Kovács M, Tóth J, Hetényi C, Málnási-Csizmadia A, and Sellers JR (2004) Mechanism of blebbistatin inhibition of myosin II. J Biol Chem 279:35557-35563.

Laser-Azogui A, Diamant-Levi T, Israeli S, Roytman Y, and Tsarfaty I (2014) Metinduced membrane blebbing leads to amoeboid cell motility and invasion. Oncogene 33:1788-1798.

Lauckner JE, Jensen JB, Chen H-Y, Lu H-C, Hille B, and Mackie K (2008) GPR55 is a cannabinoid receptor that increases intracellular calcium and inhibits M current. Proc Natl Acad Sci USA 105:2699-2704.

Lawrenson ID, Wimmer-Kleikamp SH, Lock P, Schoenwaelder SM, Down M, Boyd AW, Alewood PF, and Lackmann M (2002) Ephrin-A5 induces rounding, blebbing and de-adhesion of EphA3-expressing 293T and melanoma cells by CrkII and Rhomediated signalling. J Cell Sci 115:1059-1072.

Li D, D'Angelo L, Chavez M, and Woulfe DS (2011) Arrestin-2 differentially regulates PAR4 and ADP receptor signaling in platelets. J Biol Chem 286:3805-3814.

Luttrell LM and Lefkowitz RJ (2002) The role of beta-arrestins in the termination and transduction of G-protein-coupled receptor signals. J Cell Sci 115:455-465.

Luttrell LM, Roudabush FL, Choy EW, Miller WE, Field ME, Pierce KL, and Lefkowitz RJ (2001) Activation and targeting of extracellular signal-regulated kinases by beta-arrestin scaffolds. Proc Natl Acad Sci USA 98:2449-2454.

Ma L, Perini R, McKnight W, Dicay M, Klein A, Hollenberg MD, and Wallace JL (2005) Proteinase-activated receptors 1 and 4 counter-regulate endostatin and VEGF release from human platelets. Proc Natl Acad Sci USA 102:216-220.

Magalhaes AC, Dunn H, and Ferguson SS (2012) Regulation of GPCR activity, trafficking and localization by GPCR-interacting proteins. $\mathrm{Br} J$ Pharmacol 165: $1717-1736$

Mihara K, Ramachandran R, Saifeddine M, Hansen KK, Renaux B, Polley D, Gibson $\mathrm{S}$, Vanderboor C, and Hollenberg MD (2016) Thrombin-mediated direct activation of proteinase-activated receptor-2: another target for thrombin signaling. $\mathrm{Mol}$ Pharmacol 89:606-614.

Moers A, Nieswandt B, Massberg S, Wettschureck N, Grüner S, Konrad I, Schulte V, Aktas B, Gratacap MP, Simon MI, et al. (2003) G13 is an essential mediator of platelet activation in hemostasis and thrombosis. Nat Med 9:1418-1422.

Morrow DA, Braunwald E, Bonaca MP, Ameriso SF, Dalby AJ, Fish MP, Fox KA Lipka LJ, Liu X, Nicolau JC, et al.; TRA 2P-TIMI 50 Steering Committee and Investigators (2012) Vorapaxar in the secondary prevention of atherothrombotic events. N Engl J Med 366:1404-1413.

Offermanns S, Toombs CF, Hu Y-H, and Simon MI (1997) Defective platelet activation in G alpha(q)-deficient mice. Nature 389:183-186.

Pinner S and Sahai E (2008) PDK1 regulates cancer cell motility by antagonising inhibition of ROCK1 by RhoE. Nat Cell Biol 10:127-137.
Policha A, Daneshtalab N, Chen L, Dale LB, Altier C, Khosravani H, Thomas WG, Zamponi GW, and Ferguson SSG (2006) Role of angiotensin II type 1A receptor phosphorylation, phospholipase $\mathrm{D}$, and extracellular calcium in isoform-specific protein kinase C membrane translocation responses. J Biol Chem 281: $26340-26349$

Ramachandran R, Mihara K, Mathur M, Rochdi MD, Bouvier M, Defea K, and Hollenberg MD (2009) Agonist-biased signaling via proteinase activated receptor-2: differential activation of calcium and mitogen-activated protein kinase pathways. Mol Pharmacol 76:791-801.

Ramachandran R, Mihara K, Thibeault P, Vanderboor CM, Petri B, Saifeddine M, Bouvier M, and Hollenberg MD (2017) Targeting a proteinase-activated receptor 4 (PAR4) carboxyl terminal motif to regulate platelet function. Mol Pharmacol 91: 287-295.

Ramachandran R, Noorbakhsh F, Defea K, and Hollenberg MD (2012) Targeting proteinase-activated receptors: therapeutic potential and challenges. Nat Rev Drug Discov 11:69-86.

Rigg RA, Healy LD, Chu TT, Ngo ATP, Mitrugno A, Zilberman-Rudenko J, Aslan JE, Hinds MT, Vecchiarelli LD, Morgan TK, et al. (2019) Protease-activated receptor 4 activity promotes platelet granule release and platelet-leukocyte interactions. Platelets 30:126-135.

Ritchie E, Saka M, Mackenzie C, Drummond R, Wheeler-Jones C, Kanke T, and Plevin R (2007) Cytokine upregulation of proteinase-activated-receptors 2 and 4 expression mediated by p38 MAP kinase and inhibitory kappa B kinase beta in human endothelial cells. Br J Pharmacol 150:1044-1054.

Sah VP, Seasholtz TM, Sagi SA, and Brown JH (2000) The role of Rho in G proteincoupled receptor signal transduction. Annu Rev Pharmacol Toxicol 40:459-489.

Sambrano GR, Weiss EJ, Zheng YW, Huang W, and Coughlin SR (2001) Role of thrombin signalling in platelets in haemostasis and thrombosis. Nature 413:74-78.

Shapiro MJ, Weiss EJ, Faruqi TR, and Coughlin SR (2000) Protease-activated receptors 1 and 4 are shut off with distinct kinetics after activation by thrombin. $J$ Biol Chem 275:25216-25221.

Siehler S (2009) Regulation of RhoGEF proteins by G12/13-coupled receptors. Br $J$ Pharmacol 158:41-49.

Stavenger RA, Cui H, Dowdell SE, Franz RG, Gaitanopoulos DE, Goodman KB, Hilfiker MA, Ivy RL, Leber JD, Marino JP Jr, et al. (2007) Discovery of aminofurazan-azabenzimidazoles as inhibitors of Rho-kinase with high kinase selectivity and antihypertensive activity. $J$ Med Chem 50:2-5.

Straight AF, Cheung A, Limouze J, Chen I, Westwood NJ, Sellers JR, and Mitchison TJ (2003) Dissecting temporal and spatial control of cytokinesis with a myosin II Inhibitor. Science 299:1743-1747.

Taniguchi M, Suzumura K, Nagai K, Kawasaki T, Takasaki J, Sekiguchi M, Moritani Y, Saito T, Hayashi K, Fujita S, et al. (2004) YM-254890 analogues, novel cyclic depsipeptides with Galpha(q/11) inhibitory activity from Chromobacterium sp. QS3666. Bioorg Med Chem 12:3125-3133.

Thibeault PE, LeSarge JC, Arends D, Fernandes M, Chidiac P, Stathopulos PB, Luyt LG, and Ramachandran R (2020) Molecular basis for activation and biased signaling at the thrombin-activated GPCR Proteinase Activated Receptor-4 (PAR4). J Biol Chem 295:2520-2540.

Tinevez J-Y, Schulze U, Salbreux G, Roensch J, Joanny J-F, and Paluch E (2009) Role of cortical tension in bleb growth. Proc Natl Acad Sci USA 106:18581-18586.

Voss B, McLaughlin JN, Holinstat M, Zent R, and Hamm HE (2007) PAR1, but not PAR4, activates human platelets through a Gi/o/phosphoinositide-3 kinase signaling axis. Mol Pharmacol 71:1399-1406.

Wettschureck N and Offermanns S (2005) Mammalian G proteins and their cell type specific functions. Physiol Rev 85:1159-1204.

Wong PC, Seiffert D, Bird JE, Watson CA, Bostwick JS, Giancarli M, Allegretto N, Hua J, Harden D, Guay J, et al. (2017) Blockade of protease-activated receptor-4 (PAR4) provides robust antithrombotic activity with low bleeding. Sci Transl Med 9:eaaf5294

Woulfe DS (2005) Platelet G protein-coupled receptors in hemostasis and thrombosis. $J$ Thromb Haemost 3:2193-2200.

Xu WF, Andersen H, Whitmore TE, Presnell SR, Yee DP, Ching A, Gilbert T, Davie EW, and Foster DC (1998) Cloning and characterization of human proteaseactivated receptor 4. Proc Natl Acad Sci USA 95:6642-6646.

Yang LV, Radu CG, Wang L, Riedinger M, and Witte ON (2005) Gi-independent macrophage chemotaxis to lysophosphatidylcholine via the immunoregulatory GPCR G2A. Blood 105:1127-1134.

Address correspondence to: Dr. Rithwik Ramachandran, Department of Physiology and Pharmacology, Schulich School of Medicine and Dentistry, University of Western Ontario, London, ON N6A 5C1, Canada. E-mail: rramach@uwo.ca 